\title{
SISTEMAS DE APLICACION EXTERIOR A FACHADAS PARA LA RESOLUCION DE SUS PROBLEMAS HIGROTERMICOS, FUNCIONALES Y FORMALES.
}

\author{
(EXTERIOR APPLICATION SYSTEMS FOR FAÇADES FOR SOLVING HYGROTHERMIC FUNCTIONAL \\ AND FORMAL PROBLEMS)
}

Luis Gerardo Ruiz Palomeque, Dr. Arquitecto

Carlos H. Esteban García, Arquitecto

\section{RESUMEN}

En el presente trabajo se estudia el estado actual de cuantas soluciones reales se están experimentando en la práctica para resolver el problema de la rehabilitación de fachadas que la legislación española ha abordado recientemente.

Pese a que los sistemas que aqui se exponen resultan válidos en todo el país, el trabajo se centra en aquellos que, de hecho, se han implantado o están en proceso de implantación en la ciudad de Madrid. Ello es debido a que se trata de ofrecer la perspectiva que, sobre el tema en cuestión, proporciona la propia experiencia de los autores, evitando cualquier teorización que no esté avalada por una amplia práctica profesional.

Tras un intento de evaluar la magnitud de las cifras que el problema citado puede llegar a barajar - lo que da una idea de su importancia económica en el sector de la construcción-, se centra el estudio en el análisis de los condicionamientos básicos que afectan a la rehabilitación, procediéndose a elaborar una clasificación sistematizada de las posibles soluciones en función de dos parámetros básicos: La existencia o no de cámara ventilada, y la mayor o menor ligereza de los materiales de acabado. La clasificación así elaborada incorpora prácticamente todos los sistemas que se están experimentando, lo que da pie a realizar un estudio descriptivo y comparativo de las soluciones existentes.

Entre otras conclusiones se indica la idoneidad de los sistemas con cámara ventilada por el exterior del aislamiento, y dentro de éstos, los que disponen de materiales de acabado pesados, capaces de resolver cuantas agresiones mecánicas, climáticas, químicas y de cualquier otra indole puede sufrir el conjunto rehabilitado. Sin embargo, se apuntan ventajas e inconvenientes de todos ellos, de forma que el proyectista pueda contar con el máximo de datos posible a la hora de decidir uno u otro sistema para cada problema concreto.

\section{SUMMARY}

The present state of real solutions to the problems presented by the rehabilitation of façades, recently taken up by Spanish legislation, is examined in this study.

Despite the fact that the systems herein examined are valid for the entire country, the study centres upon those which have been implanted, or are in the process of being implanted, in the city of Madrid. This is due to the fact that the authors try to offer a perspective on the subject in question taken from their own experience, thus avoiding any theorizing not backed up by extensive professional practice.

After an attempt to evaluate the numerical magnitude of the problem - an effort which gives an idea of its economic importance to the construction sector- the study centres on the analysis of the basic conditioning factors which affect rehabilitation, elaborating a systemized classification of possible solutions in terms of two basic parametres: the existence of or lack of a ventilated space (chambre), and the greater or lesser lightness of the finishing materials. This clasification incorporates practically all the systems which are presently being experimented with, thus making it a descriptive and comparative study of existing solutions.

Among others, the suitability of systems with the ventilated space to the exterior of the isolation is pointed out; and among these, those using heavy finishing materials capable of withstanding any mechanical, climatic, chemical or other type of aggression which might be suffered by the rehabilitated structure. Nevertheless, the advantages and disadvantages of all systems are noted, and in such a way that the project designer can be assured of the maximum amount of data possible when it comes time to decide on one or the other system for each specific problem. 


\section{MARCO LEGAL}

La entrada en vigor de la Norma Básica de la Edificación NBE-CT79 sobre Condiciones Térmicas de los Edificios supuso, en su momento, la aceptación legal de una serie importante de aspectos cualitativos ligados al coniort y a la habitabilidad de los mismos, que la so. ciedad venia demandando.

La profunda crisis energética de principios de los años 70 tuvo una primera respuesta legal por medio del Decreto 1490/75, en el que la Administración adopta unas medidas urgentes con el único fin de hacer frente al problema desde una perspectiva estrictamente económica. Es en 1979, con la citada NBE-CT79, cuando se aborda el problema desde un punto de vista global, dando respuesta a todos los condicionantes térmicos e higrotérmicos relativos a la edificación: $y$, devolviendo asi a aquélla, toda la racionalidad constructiva perdida en el periodo desarrollista precedente.

La única disposición transitoria incorporada en la citada Norma Básica explicita que ésta no es de aplicación en aquellos "edificios en construcción o con las licencias de construcción concedidas a la entrada en vigor de la misman; tratándose con ello de evitar la obligatoriedad retroactiva de realizar inversiones no previstas a los propietarios de inmuebles. Sin embargo, la posterior aprobación de Real Decreto 2329/1983 de 28 de Julio sobre Protección a la Rehabilitación del Patrimonio Residencial y Urbano establece, por parte de la Administración, la aceptación del compromiso de facilitar y financiar, al menos parcialmente, la adecuación constructiva y funcional de edificios con destino principal al uso de viviendas y/o dotacional comunitario, con una antigüedad mínima de diez años.

Ello supone que toda la edificación residencial construida con anterioridad a 1977 es susceptible de rehabilitación subvencionada, no resultando extraño el suponer, por haberse ejecutado con anterioridad, que la casi totalidad de la misma estará bajo los mínimos de confort higrotérmico establecidos por la NBE-CT79.

\section{LA MAGNITUD DEL PROBLEMA}

Actualmente no disponemos de datos estadísticos específicos a partir de los cuales se pueda realizar una estimación fiable del volumen de inversión que se puede movilizar en el intento de dotar a la edificación existente en estos mínimos. Es más, en el caso de MadridCapital la única estadística oficial sobre el Estado de la Edificación es el Censo del INE de 1980. En dicho Censo se clasifican los edificios en: ruinosos, en mal estado, con alguna deficiencia y en buen estado. Sobre un total aproximado de 120.000 edificios, unos 11.000 se califican como en mal estado y otros 31.500 presentan alguna deficiencia. En línea con lo anteriormente expuesto se puede suponer que, a medio plazo, pueden requerir una rehabilitación de sus fachadas unos 42.500 edificios, equivalentes a un número próximo a las 343.000 viviendas, considerando la media oficial de dicho Censo de 8,07 viviendas/edificio. Aplicando un costo medio por vivienda de 400.000 ptas. (adecuado para el sistema más económico de los que más adelante expondremos) ello supone una inversión de 137.200 millones de pesetas. En cualquier caso, una co. ta mínima sería la obtenida a partir del supuesto de que tan solo los edificios en mal estado necesitarán su co. rrespondiente rehabilitación de fachadas. Ello da lugar a una inversión mínima de unos 35.500 millones de pesetas.

La extrapolación de estas cifras, obtenidas para Madrid-Capital, a todo el Estado, dé una ligera idea del importantisimo potencial económico que este subsector de la construcción presenta; $y$, por otro lado, del enorme compromiso adquirido por la Administración con la aprobación del citado Real Decreto 2329/83 sobre Rehabilitación del Patrimonio Residencial.

Sin embargo, es muy difícil evaluar cuántos propietarios de inmuebles pertenecientes al Sector Privado decidirían, en un plazo dado, emprender Obras de Rehabilitación en los mismos; $y$, en consecuencia, cuál va a ser la demanda de subvenciones a que ha de hacer frente la Administración. Por otra parte, los compromisos de ésta son más fuertes, en términos relativos, en lo referente a todas aquellas viviendas que han sido construidas por medio de la Promoción Pública.

Según el Censo del INE, arriba citado, en Madrid. Capital existían, en 1980, 2.265 edificios de vivienda pública en mal estado y 7.394 con alguna deficiencia, de entre un total aproximado de 18.000 edificios. Los datos relativos a viviendas, facilitados por el INSTITUTO DE LA VIVIENDA DE MADRID (COMUNIDAD AUTONOMA), cifran el monto del Patrimonio de Promoción Pública entre las 100 y 120.000 viviendas, cuyas fechas de construcción y situación legal de la Propiedad se distribuyen de la forma siguiente:

1) $30 \%(30-36.000$ viv.) construidas en la década de los años 60 y correspondientes a Unidades Veci. nales de Absorción. Se trata de viviendas de muy baja calidad constructiva y estándar superficial muy reducido.

Se encuentran en proceso de acceso diferido a la propiedad o en alquiler, por lo que la responsabilidad de su mantenimiento y adecuación constructiva y funcional corresponde directamente a la Administración.

2) $35 \%$ (35-42.000 viv.) construidas al final de la década de los 60 y principios de los 70 (a partir de 
1972 existe un vacio de promoción hasta 1979). Son, en general, de mejor calidad y mayor superficie que las del primer grupo, pero todavía anteriores a la entrada en vigor de la Norma NBE-CT79. Cedidas en propiedad por la Administración a los beneficiarios, cabe la discusión de quién sería el responsable de su futura adecuación. Sin duda, y dadas las bajas rentas de sus ocupantes, la Comunidad de Madrid puede suponer que tiene una responsabilidad subsidiaria sobre esta cuestión, al menos en términos de financiación y promoción, aunque quepan negociaciones sobre la repercusión económica de los costos.

3) $30 \%$ (30-36.000 viv.) construidas a partir de 1979 dentro del Programa de Barrios en Remodelación. Se trata de viviendas de buen estándar superficial y calidad constructiva adecuada, en las que se cumple la normativa NBE-CT79. A su vez, se encuentran cedidas en propiedad, por lo que no es previsible que requieran, de forma global, inversiones para su rehabilitación en un período razonable.

4) 5\% (5-6.000 viv.) a construir en nuevas operaciones de remodelación que habrán de ejecutarse con arreglo a la normativa vigente $y$, por tanto, tampoco son susceptibles de rehabilitar a plazo medio.

Aplicando los costos manejados con anterioridad por unidad de vivienda, se concluye que la Administración tiene que comprometer, en este sentido, entre un minimo de 12.000 y un máximo de 31.200 millones de pesetas, tan sólo en la ciudad de Madrid. En consecuencia, son de capital importancia económica cuantas decisiones se tomen al respecto, tanto desde el punto de vista de la eficacia del sistema elegido para resolver los problemas planteados, como desde el de sus costos de mantenimiento y reparación que, al menos en el $30 \%$ de viviendas del primer grupo, seguirán siendo responsabilidad de la Administración.

En este sentido, es de observar que la media de vivien. das por edificio detectada se eleva tan sólo a 8,07 en el conjunto de la ciudad, y es menor de 7 en el sub. conjunto de las viviendas de Promoción Pública. Ello equivale a afirmar que una gran mayoría de las mismas se ubican en edificios de menos de cuatro plantas, entendiendo sinónimos los términos de portal y edificio, y suponiendo una distribución de dos viviendas por escalera y planta; lo que, en conjunto, no es muy lejano a la realidad.

Como consecuencia, se pueden tomar en consideración sistemas de rehabilitación pesados que, como más adelante veremos, aportan, en muchos casos, importantes ventajas respecto a los ligeros.

\section{CONDICIONANTES}

El primer condicionante que afecta a las obras de rehabilitación de fachadas es el hecho de que, en la casi totalidad de los casos, éstas deben realizarse desde el exterior del edificio, evitándose la intervención desde viviendas, en general, habitadas. Ello produce un pequeño sobrecosto en cuanto a la repercusión del andamiaje, pero presenta la ventaja de que no se produce ningún deterioro de aquéllas $y$, fundamentalmente, no se provocan molestias innecesarias a los usuarios de las mismas.

Paralelamente, la aplicación del aislamiento por el exterior de los paramentos existentes ofrece, como es sabido, una mayor calidad y eficacia en sus resultados. Ello es debido, de un lado, a la casi total supresión de puentes térmicos que se consigue, y de otro, al aprovechamiento de la inercia térmica de los cerramientos situados al interior del aislamiento.

Tomando en cuenta consideraciones arquitectónicas, la realización de obras de rehabilitación en la fachada proporciona la oportunidad de renovar completamente su apariencia externa. Ello implica, desde la perspectiva del profesional, el hecho de que, en general, se trata de trabajos con una importante carga de diseño, que los hace, simultáneamente, atractivos y comprometidos; siendo, tanto mayor la carga de compromiso, cuanto más valioso sea el entorno urbano en que se sitúa el edificio. En este sentido, el condicionante de la integración arquitectónica en el medio circundante puede influir de forma decisiva en la elección del sistema adecuado, o, cuando menos, en la elección del material de acabado a instalar.

Por último, cabe destacar el hecho de que, en el contexto europeo, España se ha incorporado con cierto retraso en la adopción de medidas legales encaminadas al ahorro energético y al fomento de las obras de rehabilitación. Las consecuencias más inmediatas de ello son las siguientes:

1.) Casi todos los sistemas que se están implantando cuentan con patentes o documentos de "Agrement Technique" extranjeros y utilizan materiales fabricados y comercializados en diversos paises de Europa (principalmente Francia y Bélgica), lo que abunda aún más en la dependencia tecnológica de nuestro país.

2.) Estos sistemas están ampliamente experimentados en los paises de la C.E.E., cuyas variaciones climáticas estacionales no son tan extremas como en España y, particularmente, en Madrid. La implantación directa de aquéllos en nuestras latitudes puede dar lugar a problemas de instalación ylo de durabilidad, para cuya constatación 
y detección aún no ha transcurrido el período de tiempo suficiente.

Ambos aspectos, dependencia tecnológica y falta de experimentación previa, aconsejan una gran cautela a la hora de decidir el sistema a emplear, y, en cualquier caso, requieren por parte de cuantos están implicados en el problema (Arquitectos, Empresas Constructoras, Promotores Privados y Administración), la búsqueda de soluciones autóctonas y ajustadas a la agresividad climática de nuestro país.

\section{SISTEMAS EXISTENTES. CLASIFICACION. ESTUDIO COMPARATIVO}

El espectro real de soluciones aplicadas al problema de la rehabilitación de fachadas en Madrid-Capital es, en estos momentos, muy reducido, comprendiendo únicamente cuatro sistemas concretos. Sin embargo, éstos cubren la casi totalidad de las posibilidades de respuesta, atendiendo a la clasificación teórica que se propone más abajo. Esta se basa en dos parámetros fundamentales a la hora de caracterizar el funcionamiento, diseño y construcción de los correspondientes sistemas. Un primer parámetro es el hecho de que el sistema rehabilitador disponga o no de una cámara de aire intermedia; $y$, en caso afirmativo, el que ésta se sitúe por el exterior o por el interior del material aislante. Como más adelante veremos, la existencia y situación de esta cámara confiere posibilidades funcionales y problemáticas constructivas muy distintas a las soluciones adoptadas. El segundo parámetro es el peso del material de acabado superficial, que condiciona fuertemente el diseño, por razones de durabilidad, de posible reducción de espesores del material aislante y de resistencia de las solicitaciones existentes sobre las fijaciones a la fachada, entre otras.

Dado que nuestra intención es mostrar el estado actual de la cuestión, no entraremos en la discusión de posibles alternativas, sino sólo en la comparación y estudio de las soluciones realmente experimentadas o en vias de próxima experimentación. Asimismo no se incluyen en este trabajo todas aquellas soluciones relativas a la inyección de materiales aislantes en cámaras, dado que, entre otros problemas que pueden presentar, no suponen una respuesta integral rehabilitadora.

Atendiendo a los parámetros citados, los posibles sistemas y los realmente empleados se pueden clasificar como sigue:

A) SISTEMAS SIN CAMARA. Son siempre sistemas con acabado ligero y están representados por el que Ilamaremos sistema poliestireno-MORTERO (PM).
B) SISTEMAS CON CAMARA EXTERIOR, que se pueden subdividir en:

B-1 SISTEMAS LIGEROS, representados por el sistema VENTISOL-GALVA (VG).

B-2 SISTEMAS PESADOS, representados por el doblado con muro de ladrillo, al que llamaremos sistema MD.

C) SISTEMAS CON CAMARA INTERIOR, que se pue. den subdividir en:

C-1 SISTEMAS LIGEROS, representados por el panel de doble capa de hormigón reforzado con fibra de vidrio (GRC).

C-2 SISTEMAS PESADOS, que en la actualidad no han sido diseñados ni experimentados.

Con independencia del estudio que, al hablar de cada sistema en concreto, realizaremos con respecto a sus correspondientes ventajas e inconvenientes, cabe una discusión previa acerca de la conveniencia de disponer o no de la citada cámara de aire, $y$, decidida ésta, sobre su situación idónea. En este sentido se puede afirmar que no sólo es deseable, sino incluso inevitable, el considerar que dicha cámara ha de estar al menos "débilmente ventilada", en los términos descritos por el Anexo 2 de la NBE-CT79. Dicha cámara debe, por tanto, diseñarse con la ventilación prevista de antemano por las ventajas que ello supone, y que más adelan. te veremos; dado que, en caso contrario, las dilatacio. nes y retracciones de los materiales de acabado a plazo medio acabarán permitiendo el paso del aire por sus juntas, por muy cuidadosa que haya sido la ejecución de su sellado.

Las cámaras suelen ejecutarse con espesores situados entre los 20 y $50 \mathrm{~mm}$ a fin de que la débil corriente de aire establecida en su interior se produzca en régimen laminar y no sea posible la formación de corrien. tes de convección.

Las funciones más importantes que, entre otras, cumple la cámara de aire son las siguientes:

-El edificio a rehabilitar constituye una gran masa, ejecutada por lo común de una sola vez que, durante el período previo a su rehabilitación, ha sufrido, de forma conjunta, los movimientos y reajustes necesarios. A él se sobrepone una cáscara nueva, con una masa mucho menor y materiales, en algunos casos, muy distintos. Cuando la nueva fachada se ejecuta con materiales pesados y/o frágiles, la interposición de la cámara favorece una relativa independencia de movimientos del sistema sobrepuesto, amortiguando y minimizando el potencial peligro de 
roturas en éste por los posibles movimientos diferenciales a que hubiera lugar.

- La cámara de aire permite, con sus posibles variaciones de espesor, corregir los plomos y alineamientos de la fachada preexistente que, comúnmente, presentará una ejecución poco cuidada. Ello redunda en una mejor calidad final del acabado resultante.

- Los cálculos disponibles, realizados en torno a la trasmisión de humedad a su través y a la evitación de humedades de condensación (Ref. 6), muestran que este reducido espacio ventilado es suficiente para lograr el permanente secado del material aisian. te. Por consiguiente, si la cámara se sitúa en la cara exterior de éste, disipará la humedad antes de que penetre en él, manteniendo íntegra su capacidad aislante, que, como sabemos, depende en mayor o menor medida de su contenido de humedad (el poliuretano es muy sensible a ella). Si, por el contrario, la cámara se sitúa en el trasdós del aislamiento, sólo disipará la humedad una vez que, proviniente del exterior, haya empapado la masa del mismo estableciendo un flujo permanente de vapor en sentido exterior-interior.

- La disposición de un espacio ventilado al exterior del aislamiento y en contacto directo con el material de acabado minimiza las cargas térmicas sobre el sistema (Ref. 6), dado que el calor absorbido por este último es disipado en el aire de la cámara, y se crea una corriente ascendente de aire caliente que se expulsa permanentemente por los orificios previstos al efecto en la coronación del edificio. La situación del aislamiento en contacto directo con el edificio impide la pérdida de energía interna por este procedimiento, cosa que sí tiene lugar cuando aquél se coloca el exterior de la cámara.

- No disponemos de datos experimentales o empíricos que cuantifiquen con exactitud las relaciones entre grado de ventilación y espesor de la cámara, con el descenso de cargas térmicas o las pérdidas de energía interna del edificio en función de su colocación dentro del sistema. Sin embargo, sí podemos concluir que la situación de la CAMARA AL EX. TERIOR DEL AISLAMIENTO es mucho más ventajosa que la contraria, en función de que impide la humectación de aquél, conserva intacta toda su capacidad aislante, reduce la incidencia de las cargas térmicas sobre el edificio - lo que permitiría considerar una reducción del espesor del aislante-, y no provoca pérdidas no previstas e indeseables de la energia producida desde el interior, que, en general, es muy costosa.

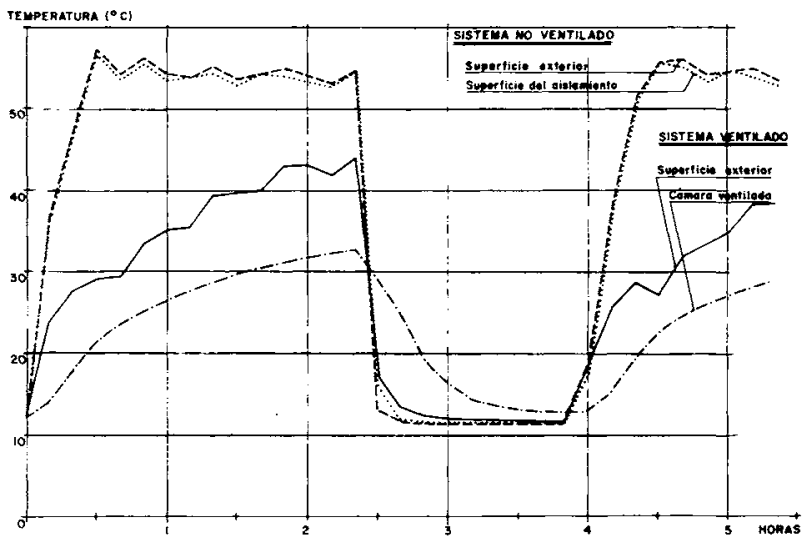

Fig. 1.- Variaciones de temperaturas en sistemas ventilados y no ventilados sometidos a ciclos de calor.

- La disposición de la cámara de aire entre el material de acabado y el aislamiento impide que cualquier daño, rotura o fisuración producida en el primero, redunde en una pérdida de la eficacia del segundo, entre otras causas por la simple trasmisión de la humedad exterior por contacto directo.

- Existen datos experimentales comparativos del distinto comportamiento de sistemas con cámara y sin cámara ante incrementos cíclicos de calor. En la figura 1 (Ref. 6) se observa cómo un sistema no ventilado alcanza mayores temperaturas de una forma mucho más rápida que un sistema ventilado. Este resulta más inerte ante la absorción de calor. Asimismo, es posible ver cómo en los sistemas no ventilados las temperaturas medidas en su cara exterior y en la superficie del aislamiento son prácticamente iguales. Por el contrario, en los sistemas ventilados, la cámara de aire tiene temperaturas mucho menores que la superficie exterior de acabado, lo que indica que el aislamiento ha de enfrentarse a condiciones climáticas mucho menos agresivas en su entorno inmediato. En conclusión, el sistema ventilado, a igualdad de espesor de aislamiento, es mucho más eficaz 0 , por el contrario, dado un coeficiente $\lambda$ prefijado, requerirá menos espesor de aislamiento.

En resumen, también se puede concluir que los SISTEMAS CON CAMARA EXTERIOR AL AISLAMIENTO son mucho más ventajosos que los que no disponen de tal cámara, resultando, por tanto, ser aquellos los que resuelven en condiciones idóneas el problema planteado, y su empleo queda recomendado desde aqui al efecto. Pese a ello, en los apartados siguientes veremos, al analizar las ventajas e inconvenientes de los sistemas al uso, cómo otra serie de razones de diversa índole puede conducir a una toma de decisión diferente de la recomendada. 


\section{SISTEMAS SIN CAMARA. EL SISTEMA POLIESTIRENO-MORTERO (PM)}

De forma esquemática el sistema PM se puede describir como un material aislante (comúnmente poliestireno expandido en planchas) adherido directamente a la fachada base existente, y recubierto al exterior por una capa delgada de mortero modificado, armado con malla de fibra de vidrio, y posteriormente pintado.

Se trata, sin duda, del sistema de mayor difusión, en cuanto a su número de aplicaciones reales, tanto en España como en el resto de Europa, donde cuenta con una extensa tradición de empleo. Es por ello que en mayo de 1979 la Union Europeenne pour l'Agrèment Technique dans la Construction (UEAtc), elabora las "Directrices para Sistemas de aislamiento exterior de fachadas con revestimiento delgado sobre aislamienton, en que se fijan las normas generales de calidad del sistema y los ensayos de identificación de productos y de aptitud de empleo necesarios. El Instituto Eduardo Torroja (IETCC), como miembro de la UEAtc, participó en su momento en la elaboración de estas directrices, con arreglo a las cuales concede los correspondientes Documentos de Idoneidad Técnica a las empresas que así lo solicitan. En la actualidad existen en España no menos de siete casas especializadas que comercializan el sistema con los correspondientes D.I.T.

Además de la experiencia largamente adquirida en los paises europeos, y particularmente en Francia, el sistema posee abundante literatura técnica que recoge, tanto sus aspectos de puesta en obra, como sus condiciones de ejecución, las faltas de calidad más usuales y la forma de corregirlas. En este sentido son de destacar los textos de P. Baronnie, Ingeniero del CSTB, cuyo "Manual para la puesta en obra de revestimientos sobre Aislamiento. El buen ejemplo del aplicador K'APLIC" ha sido traducido recientemente por el IETcc, y constituye una guia sencilla y práctica de fácil lectura.

En la correcta aplicación de este tipo de sistemas resulta determinante la buena adherencia entre el aislante y la fachada preexistente, de forma tal que su durabilidad y buen funcionamiento dependen directamente de ella. El soporte debe encontrarse, en el momento de la colocación del aislante, totalmente limpio, libre de polvo y grasas, con una superficie sin irregularidades superiores a $1 \mathrm{~cm}$ y con sus posibles fisuras retacadas. Los acabados a base de enfoscados, revocos y pinturas orgánicas en mal estado son particularmente peligrosos, dada su posible mala adherencia a la base de albañilería. En ellos es preciso realizar un sondeo de toda la superficie, picando y reparando los abolsamientos existentes y, si es preciso, procediendo al decapado y posterior lavado de la superficie. Las (C) Consejo Superior de Investigaciones Científicas Licencia Creative Commons 3.0 España (by-nc) operaciones de control y limpieza de los soportes existentes resultan lentas y, en general, muy costosas, dado que consumen gran cantidad de horas de mano de obra. Es por ello que se requiere una estrecha vigilancia en su ejecución y, en cualquier caso, la realización a posteriori de ensayos in situ de arrancamiento. Estos deben realizarse conforme a lo descrito por las di. rectrices de la UEAtc en, al menos, dos series de cinco muestras situadas en superficies representativas. En ninguna muestra resultarán admisibles tensiones de arrancamiento inferiores a $3 \mathrm{kp} / \mathrm{cm}^{2}$, debiendo producirse éste en más de la mitad de los casos en planos distintos al de encolado.

La adherencia da las planchas de poliestireno al soporte se confía a un doble sistema. Por una parte, se encolan por medio de adhesivos que, comúnmente, se componen a base de la mezcla de cemento Portland 350 (al $30 \%$ del peso) con una pasta acuosa formada con cargas mineales y aditivos, que utiliza como ligante principal un copolímero acrílico tipo látex, en dispersión. La técnica de encolado depende del estado y pla. neidad del soporte. Por otra parte, el encolado se suplementa con la instalación de fijaciones mecánicas en forma de rosetas de nylon, a razón de 5 unidades por plancha (una en el centro y otra próxima a cada esquina). Es de advertir que el encolado resulta imprescindible, no siendo el empleo de rosetas más que un elemento de seguridad que no puede sustituir a aquél. Las operaciones de encolado deben realizarse por encima de $\operatorname{los} 5^{\circ} \mathrm{C}$, por debajo de los $30^{\circ} \mathrm{C}$ y antes de que transcurra $1 \frac{1}{2} \mathrm{~h}$ desde la preparación del mortero, a fin de que éste conserve íntegramente sus propiedades.

Las placas de poliestireno expandido serán de material autoextinguible y estabilizado, según la norma UNE 53127 , con clasificación de reacción al fuego M1. Es recomendable el empleo de marcas en posesión del sello de Calidad del INCE y, en cualquier caso, la certificación del fabricante de la satisfacción del tiempo de curado minimo que garantice la necesaria estabilidad dimensional de aquéllas.

El revestimiento exterior se realiza normalmente con un mortero modificado idéntico al empleado como adhesivo para las placas. Tras el secado del material de adhesión (24 h), se procede a aplicar sobre las mismas una primera capa de revestimiento, instalándose la malla de arriba a abajo y con solapes mínimos de $10 \mathrm{~cm}$, estando aún la pasta fresca. Con posterioridad al secado de esta capa ( $24 \mathrm{~h}$ ) se recubre la malla con una segunda capa de revestimiento para proteger y alisar perfectamente la superficie. Sobre ella se extiende el posterior acabado definitivo a base de pintura o enfos. cados con texturas de mayor o menor potencia. Es de advertir que a esta capa se confía la protección e im. permeabilidad del conjunto, por lo que es preciso un http://informesdelaconstruccion.revistas.csic.es 


\section{SISTEMA PM. DETALLES CONSTRUCTIVOS.}
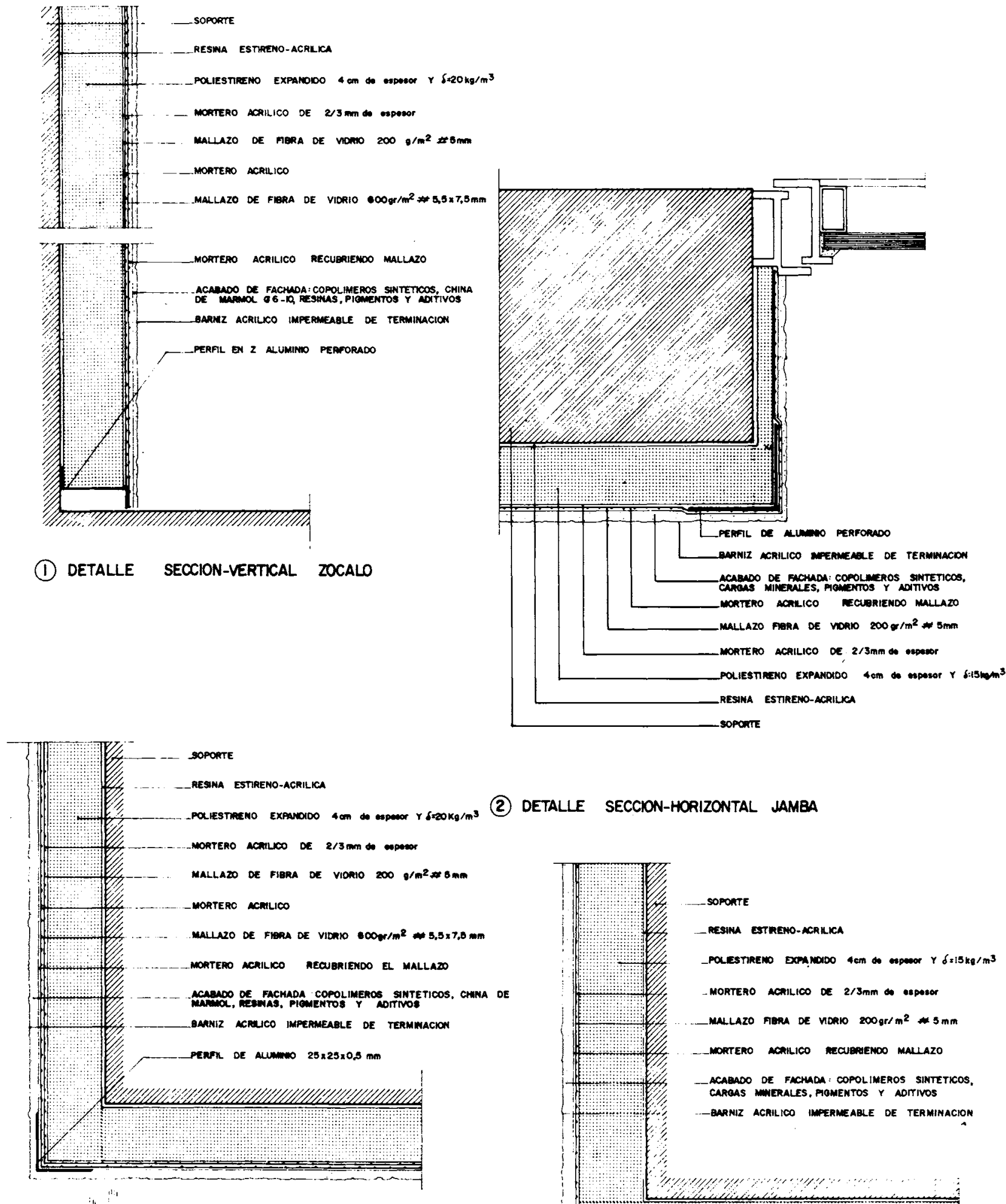

(3) Detalle seccion-horizontal angulo de fachada (Zonos bojas)

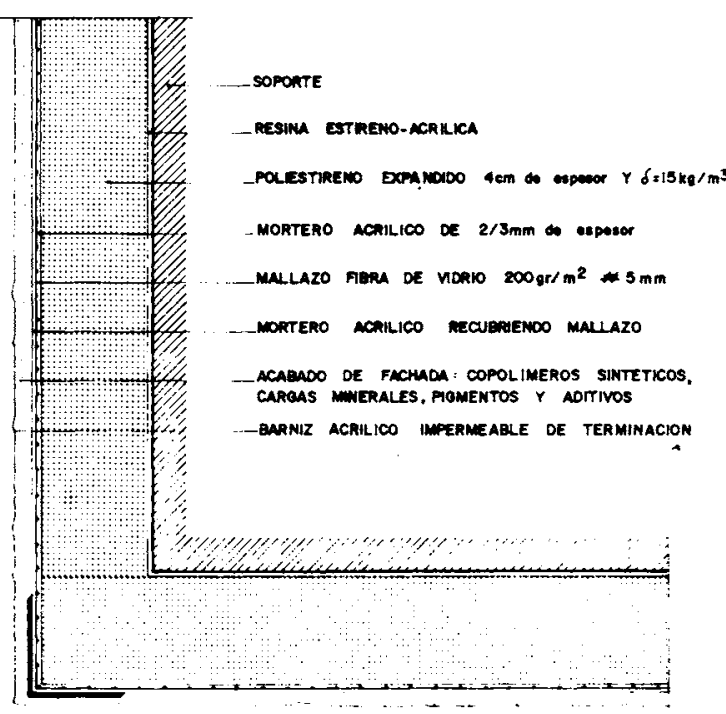

(4) DETALLE SECCION-HORIZONTAL ANGULO DE FACHADA (Zonos altos) 
estricto control de su espesor $(2,5-3 \mathrm{~mm})$ y de su adecuada puesta en obra. En este sentido resultan muy comunes dos defectos de ejecución encaminados a evitar el coste de mano de obra que supone la ejecución en dos capas. El primero consiste en la instalación de la malla en contacto directo con el aislamiento, procediéndose a aplicar tan sólo la capa exterior, y el segundo en la aplicación de una sola capa previa, en la que se embebe la malla presionándola fuertemente con la llana.

Los detalles de este sistema (jambas, juntas de dilatación, encuentros con zócalos y cubiertas, etc.) están suficientemente estudiados, resultando particularmente sencillos de ejecución, y se reflejan en toda la documentación referenciada al final del texto.

El acabado de este sistema presenta una superficie homogénea y continua, carente de juntas, con un aspecto de enfoscado liso o rugoso. Ello le hace adecuado en medios urbanos, donde predominan los acabados similares y los revocos.

Supuesto un soporte a base de un pie de ladrillo perforado y un aislamiento rehabilitador, realizado con planchas de porexpan de $4 \mathrm{~cm}$ de espesor y de 15 $\mathrm{kg} / \mathrm{m}^{3}$ de densidad (que suele ser el de normal instalación), el muro final resultante posee un coeficiente de conductividad térmica de $0,544 \mathrm{kcal} / \mathrm{m}^{2}{ }^{\circ} \mathrm{C}$.

Realizado el correspondiente estudio, no se detecta la posibilidad de aparición de condensaciones intersticiales en el sistema.

Las ventajas más importantes de este tipo de sistemas son las siguientes:

- Sencillez de ejecución, flexibilidad y fácil adaptación a cualquier modulación de fachada preexistente.

- Buena prevención de los puentes térmicos.

- Reducido espesor (no mayor de $5 \mathrm{~cm}$ ). Ello permite su utilización sin gran consumo de espacio exterior, lo que es interesante en el caso de fachadas con alineación directa en la vía pública.

- Economia de instalación debida a su sencillez, a la falta de necesidad de estructura portante, y a la poca repercusión de los medios auxiliares de elevación, entre otras causas.

Los inconvenientes más importantes de que adolece son los siguientes:

- Se trata de un sistema no ventilado con los inconvenientes anteriormente apuntados.
- No es resistente al fuego.

- El sistema es muy blando y no resiste pequeños impactos. Su empleo en plantas bajas y otras zo. nas vulnerables de la edificación requiere la adop. ción de medidas de refuerzo, como son las siguientes:

- Aumento de la densidad del aislamiento.

- Refuerzo de la malla de fibra $\left(200 \mathrm{gr} / \mathrm{m}^{2}\right)$ con otra blindada de $720 \mathrm{gr} / \mathrm{m}^{2}$.

- Acabado superficial pétreo con china de mármol proyectada de $\varnothing 3-6 \mathrm{~mm}$.

La adopción conjunta de todas estas medidas redunda en un importante sobrecosto de la solución final y no garantiza con total seguridad la invulnerabilidad del sistema, aun cuando mejora su comportamiento.

- Los copolímeros acrílicos presentan cadenas abiertas inestables en el tiempo. Su tendencia a cerrar cadenas produce una retracción del material con la consiguiente aparición de microfisuras que per. meabilizan la superficie exterior. Las variaciones climáticas fuertes (temperaturas, humedad...), actuando cíclicamente, aceleran el envejecimiento de estos copolímeros.

- La penetración de humedad, por ésta u otras causas, agrede directamente al material aislante, reduciendo su coeficiente $\lambda, y$, dada la continuidad de todos los componentes del sistema, puede colap. sar, aunque sea localmente, el funcionamiento del conjunto.

- Los problemas citados de resistencia superficial y envejecimiento implican la toma en consideración de costos de mantenimiento que, hoy por hoy, no están evaluados, pero que es previsible que resulten muy superiores a los de otros sistemas.

- Los materiales básicos del adhesivo y la malla de fibra de vidrio (que debe estar dotada de la corres. pondiente protección antialcalina) son de fabricación extranjera, y en muchos casos, en situación casi monopolista. Ello obliga a la importación de los mismos y a la consiguiente dependencia tec. nológica del exterior.

Este sistema se está empleando de forma masiva en la rehabilitación del Barrio de San Blas, en Madrid, por parte de la Comunidad Autónoma (San Blas es la concentración más fuerte de vivienda pública del Estado); y se ofrece documentación gráfica de un proyecto, en este barrio, realizado por los autores de este artículo $y$ otros arquitectos. 


\section{SISTEMAS LIGEROS CON CAMARA EXTERIOR. EL SISTEMA VENTISOL-GALVA (VG)}

El sistema consta especificamente de un material aislante (lana de vidrio, poliestireno expandido, o poliuretano proyectado) adherido directamente a la fachada base existente, pero que, en este caso, no sirve como soporte del acabado superficial. Este está constituido por placas de GLASAL (amianto-cemento fabricado a altas presiones y coloreado exteriormente) remachadas a una estructura vertical de perfiles ligeros de chapa plegada de acero galvanizado. El anclaje de la misma se realiza en los niveles de forjado y en puntos intermedios con escuadras de longitud regulable, también de acero galvanizado.

Este sistema, y otros análogos, han sido homologados en Bélgica por la empresa Eternit. Actualmente se está empezando a instalar, por primera vez en España, en la Rehabilitación de Fachadas Exteriores de 820 viviendas en el Poligono de Sta. Ana-Fuencarral de Madrid, con proyecto de los autores de este artículo. La implantación en nuestro país del sistema, suficientemente experimentado en Europa, ha requerido una serie de modificaciones respecto a la patente original, a fin de adaptarlo al clima y a la realidad industrial española.

En cuanto al material aislante, el sistema homologado considera el empleo de mantas de fibra de vidrio, pero sus peores condiciones aislantes, sus mayores dificultades de instalación y sus menores garantías de adherencia al soporte, han aconsejado su sustitución por planchas de poliestireno expandido (EPS), colocadas con una técnica similar a la indicada para el sistema PM.

Sin embargo, en este caso, y en todos los sistemas dotados de cámara exterior, cabe considerar la posibilidad de utilización del poliuretano proyectado (PU). Ello es debido a que, como ya se ha indicado, la cámara proporciona una protección idónea para el aislamiento frente a la humedad ambiental. Como se aprecia en la Fig. 2, el poliuretano resulta ser muy sensible a aquéIla, sobre todo en términos relativos al EPS, lo que desaconseja su empleo en los sistemas no ventilados. Sin embargo si resulta competitivo, dadas sus mejores condiciones aislantes, en sistemas que, como el que nos ocupa, aseguran su protección.

En cualquier caso, ha de evitarse la absorción de humedad en el poliuretano protegiendo su superficie con un cubrimiento a base de silicona, o productos acrílicos, de un grosor medio de $0,75 \mathrm{~mm}$ y ejecutada en dos capas de aplicación cruzada, para evitar la formación de poros.

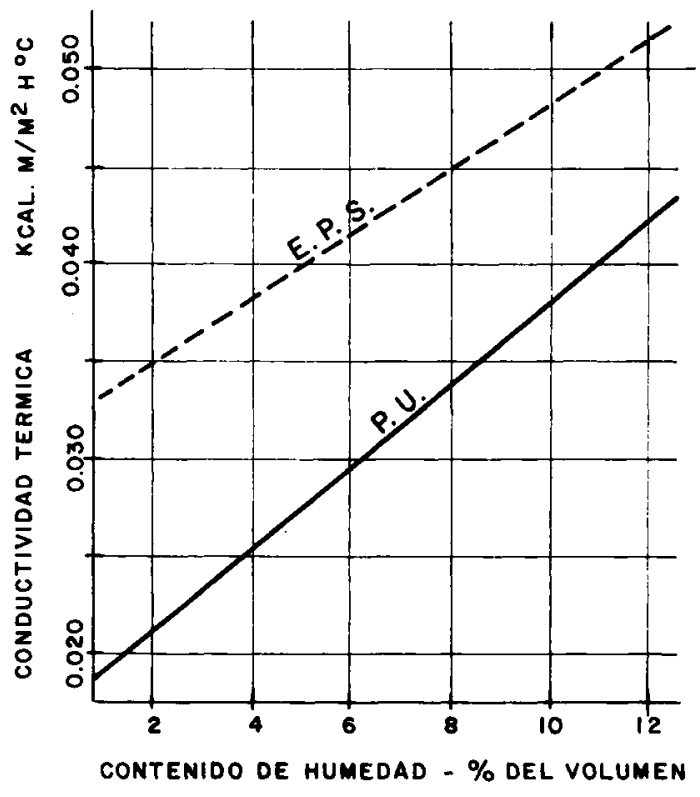

Fig. 2.- Efecto de la humedad sobre los materiales aislantes.

La proyección de poliuretano requiere el concurso de personal especializado capaz de lograr la mejor textura posible de acabado y la máxima homogeneidad del espesor de la capa de aislamiento. Las proporciones de isocianato y polyol deben ajustarse y controlarse conforme a los valores recomendables, manteniéndose constantes durante todo el proceso de aplicación. Asimismo, deben cuidarse la temperatura y la presión de los componentes, el tiempo de reacción y las características físicas del aislamiento final, ajustando el equipo a las condiciones medioambientales concretas de cada momento.

Al igual que ocurre con el poliestireno, la perfecta adherencia del poliuretano al soporte es esencial para el éxito de la solución y deben controlarse a este respecto, tanto la limpieza de la fachada existente, como la temperatura (no menor de $3^{\circ} \mathrm{C}$ ni mayor de $30^{\circ} \mathrm{C}$ ), la humedad del soporte $(<10 \%)$ y la humedad relativa del aire ( $<80 \%$ y en ningún caso en tiempo lluvioso). Es particularmente importante el control de la humedad dado que el agua reacciona con el isocianato produciendo una pátina frágil en la superficie de contacto, que reduce notablemente su adherencia. Es recomendable no proceder a la proyección de $\mathrm{PU}$ con vientos superiores a los $40 \mathrm{~km} / \mathrm{h}$, asi como utilizar pantallas protectoras por encima de los $20 \mathrm{~km} / \mathrm{h}$, dado que se pueden producir daños en áreas que no se desea aislar y se forman superficies de acabado de textura irregular y mala calidad.

La contribución del poliuretano a la extensión de la llama y el contenido tóxico de los gases producidos en su combustión aconsejan la adopción de importantes medidas precautorias al respecto; $y$, en particular, las 
SISTEMA VG. SECCIONES VERTICALES. REHABILITACION DE FACHADAS EX. TERIORES. SANTA ANA. MADRID.

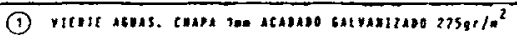

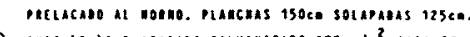

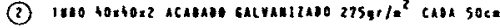
aechole con notite troyt of rivel.

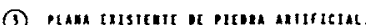

(5) rishciok nitit clare at 97392

(5) Iexate ive neste (rentisol).

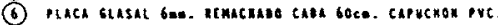

(7) ecris: 30.1 .5

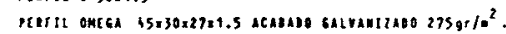
setenplanos ie ractane.

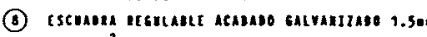

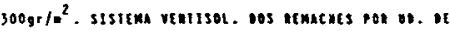

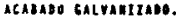

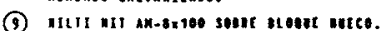

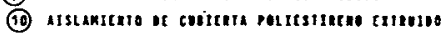

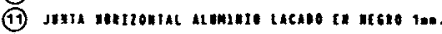

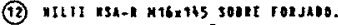

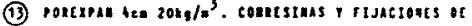
ntion.

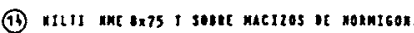

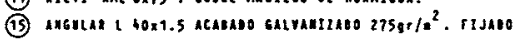
con clavo ax $\$ 7312$ cazh $50 \mathrm{cs}$.

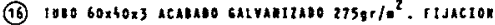
ot carplutera.

(17) cois ot persiand tristente.

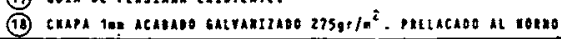

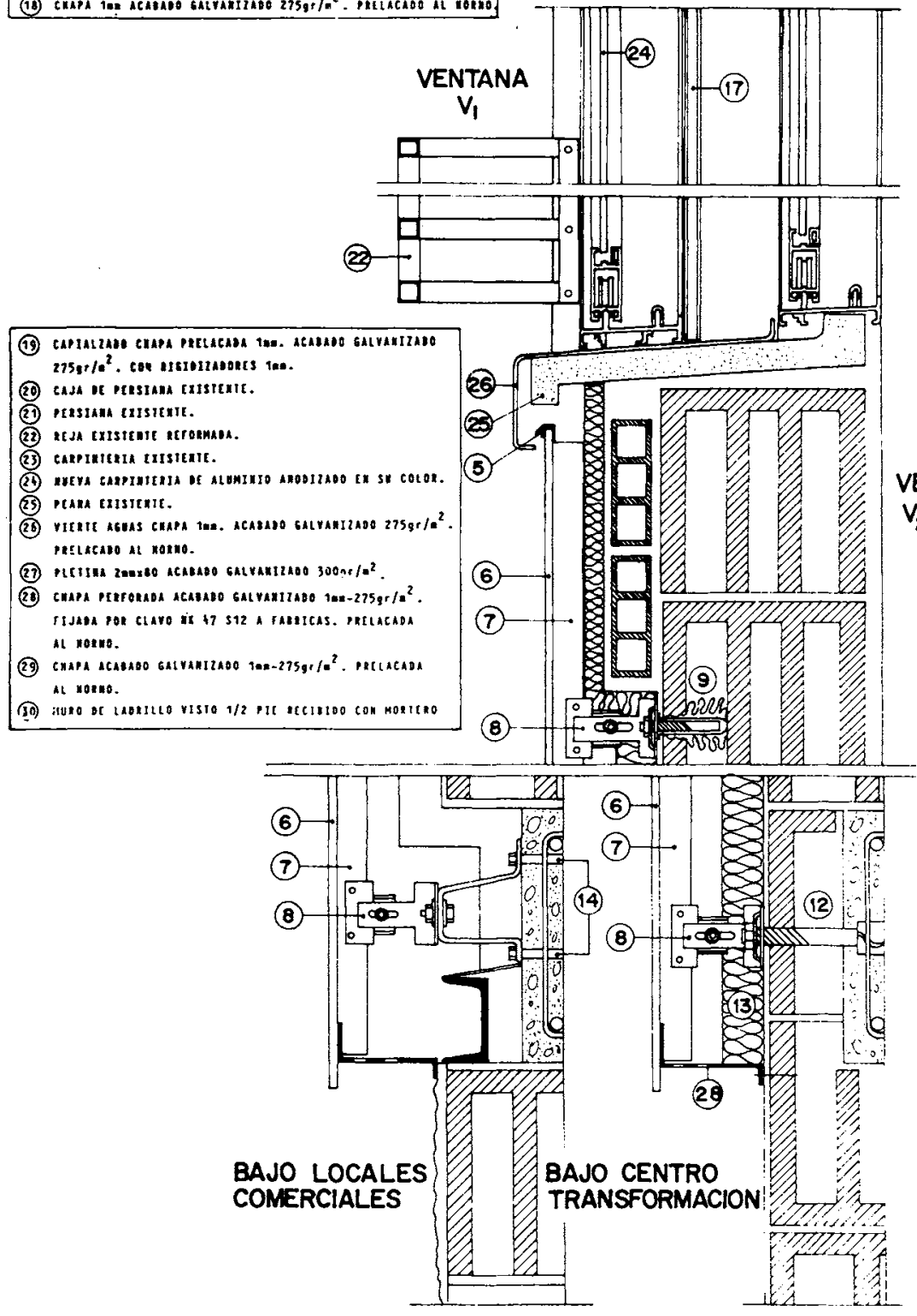

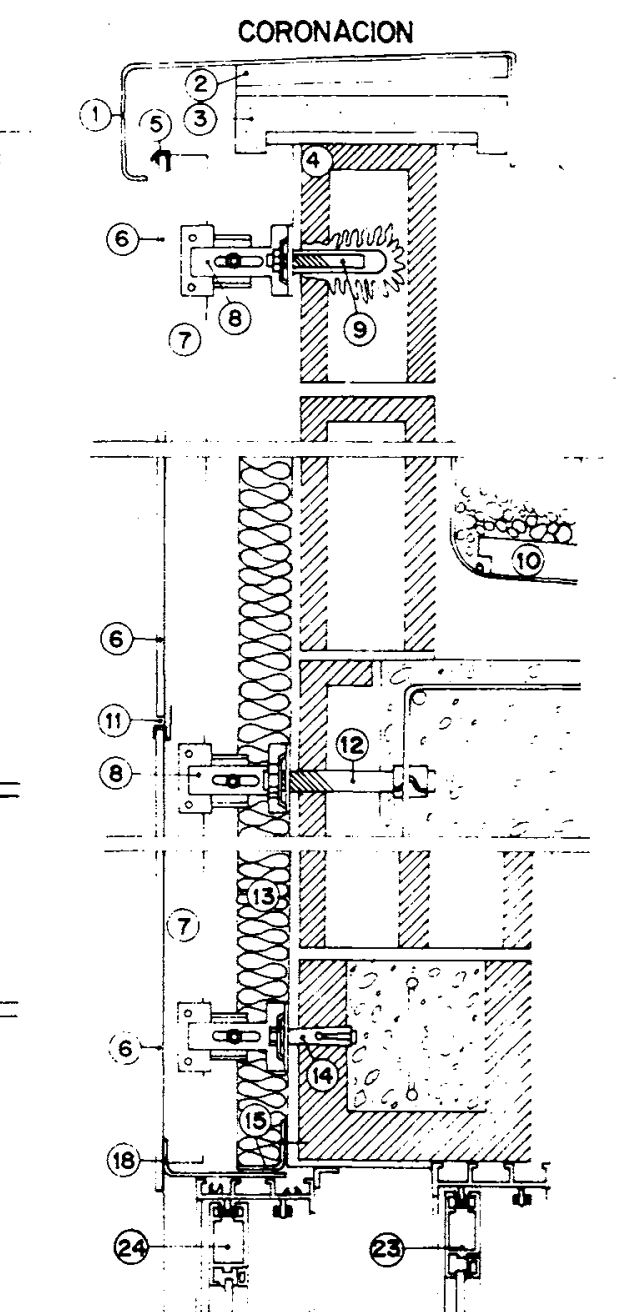

(19)

(16)
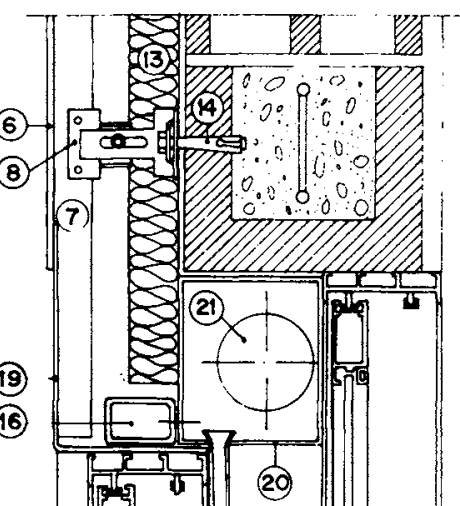

(20)

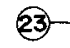

VENTÁNAS

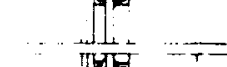

$V_{2}$ y $V_{3}$

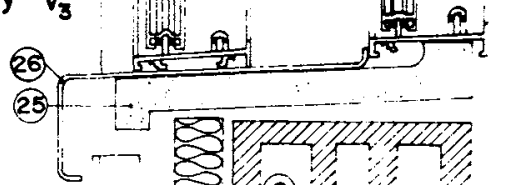

(6)- $\rightarrow$ है।

(7)

8

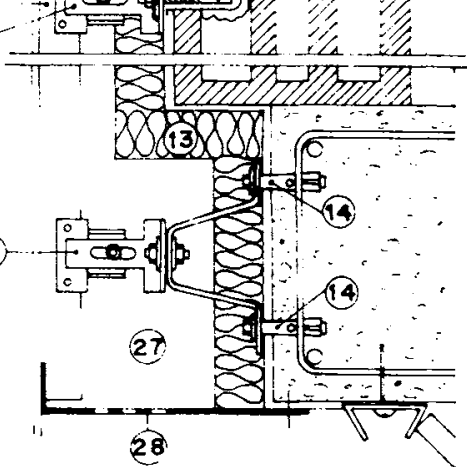

BAJO DIAFANO 
relativas a la exigencia del correspondiente tratamiento de ignifugación y la protección especial del mismo en las áreas de cocinas, principalmente en torno a la salida de gases, orificios de ventilación y huecos de las mismas.

Como todo sistema proyectado presenta la importante ventaja constructiva, en comparación con el EPS, de la facilidad de ejecución de los encuentros con las fijaciones de la estructura de fachada, la adherencia continua al soporte y la total anulación de los puentes térmicos.

En la capa de PU proyectado debe dedicarse especial atención al control del espesor de la misma (en condiciones óptimas una pulgada de PU equivale a $4 \mathrm{~cm}$ de EPS), al aspecto del acabado superficial, que es un buen indicador de su patología (ver ref. 17), a su porosidad exterior, a su tensión de adherencia (controlada con ensayos de arrancamiento) y a su densidad (30-40 $\left.\mathrm{kg} / \mathrm{m}^{3}\right)$.

Los elementos especificos de este sistema son, tanto el material de acabado, como la estructura que lo soporta y sus elementos de anclaje a la fachada, preexistente. Se acompaña en la Figura 3 un esquema de montaje del sistema conjunto.

El material de acabado exterior es el denominado GLASAL, fabricado en Bélgica por la empresa Eternit. Se trata de amianto-cemento fabricado en autoclave y con acabado exterior a base de esmalte mineral de aspecto muy homogéneo y satinado. Se fabrica en planchas de varias dimensiones, si bien las adecuadas a la obra comentada son de $305 \mathrm{~cm} \times 122 \mathrm{~cm}$ y $6 \mathrm{~mm}$ de espesor.

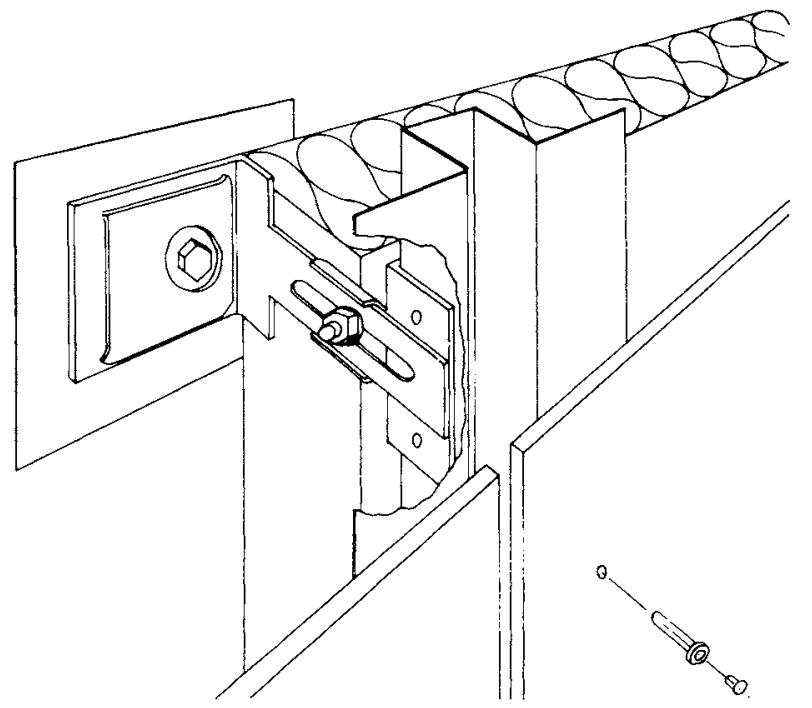

Fig. 3.- Esquema de montaje de sistema ligero con cámara.
Este material reúne una serie de caracteristicas que to hacen adecuado para la resolución del problema planteado. Entre ellas destacan las siguientes:

- Ligereza. Una placa entera pesa unos $40 \mathrm{~kg}$, lo que le hace fácilmente elevable y manejable por dos hombres sin medios auxiliares especiales.

- Resistencia a la intemperie. Su reducida porosidad (14\%) y la capa de esmalte exterior le protejen de las heladas, resultando muy resistente a los ciclos alternados de calor-frío. A su vez, el proceso de envejecimiento por mineralización del material queda muy atenuado por la capa de esmalte, lo que aumenta notablemente su durabilidad.

- Resistencia química ante los agentes agresivos medioambientales.

- Resistencia mecánica y rigidez adecuada para salvar las luces entre apoyos previstas, soportando su propio peso y los esfuerzos de viento a que va a estar sometido.

- Dilatación térmica $\left(1 \mathrm{~mm} / \mathrm{m}^{\circ} \mathrm{C}\right)$ análoga a la del acero laminado y el hormigón, por lo que no se producen importantes incrementos diferenciales de longitud entre el material, la estructura portante y el edificio preexistente.

- Fácil mecanización, que permite el corte, taladro y manipulación de las placas en un pequeño taller a pie de obra. Ello lo convierte en un material semiprefabricado, evitándose los inconvenientes de la rigidez dimensional de la total prefabricación y reduciendo costos de mano de obra frente a la total ejecución in situ.

- Estabilidad del color y fácil limpieza, que inciden en una casi nula inversión a medio plazo en gastos de mantenimiento.

Como inconvenientes del Glasal caben citar los siguientes:

- Necesidad de cuidar el transporte y posterior acopio; dado que la gran flexibilidad de las placas puede dar lugar a deformaciones permanentes en las mismas.

- Fragilidad, que se traduce en unas pérdidas medias por transporte del $5 \%$ y que obliga a un cuidadoso control de las tolerancias en las uniones, a fin de evitar la rotura por variación dimensional.

- Mayor dificultad en la ejecución de detalles especiales (jambas, juntas, remates inferior y superior) que en el sistema no ventilado, debiendo, en este 
caso, suplementarse el material general con otros plegables (como chapas de acero o aluminio) de acabado y textura análogos a los de aquél. En general, la existencia de la cámara supone una dificultad constructiva añadida en estos sistemas, que debe resolverse cuidadosamente en torno a los huecos y en el arranque y coronación del edificio.

- Escasa resistencia al impacto, y fragilidad ante el mismo, que no le hacen susceptible de utilización en plantas bajas.

- Fabricación en planchas de dimensiones prefijadas, que obliga a unas pérdidas por corte situadas en torno al $25 \%$ de la superficie a cubrir.

- Se trata de un material de importación, dado que las empresas filiales de Eternit no lo fabrican en España.

\section{SISTEMA VG. SECCIONES HORIZONTALES. REHABILITACION DE FACHADAS} EXTERIORES. SANTA ANA. MADRID.
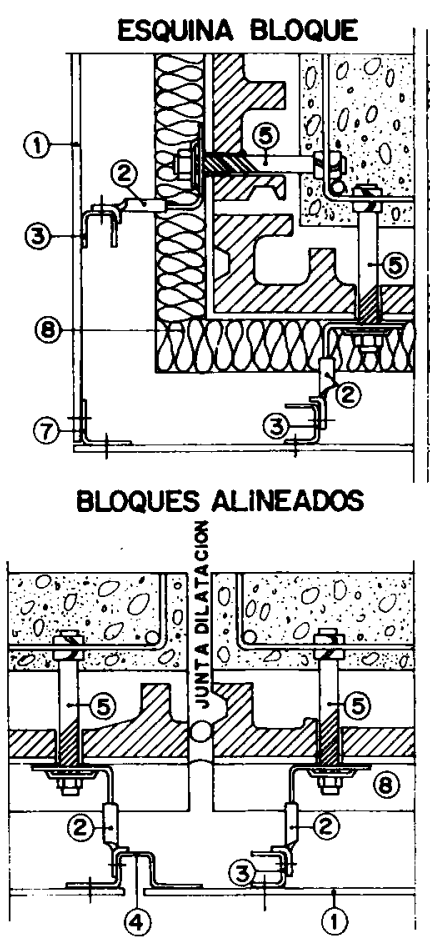

BLOQUES RETRANQUEADOS

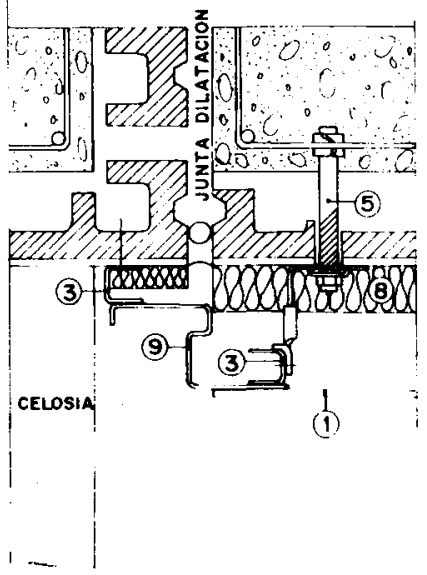

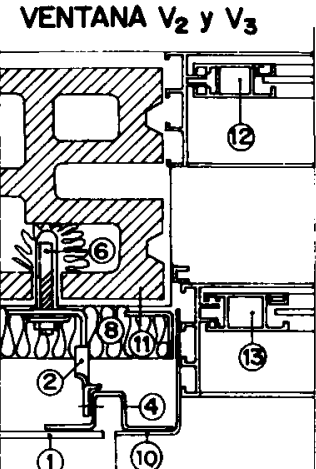

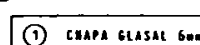

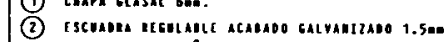

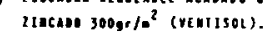

(3) PEeriL Acaseso Gatrantzado $30 \times 30 \times 1.5$

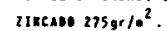

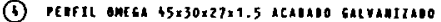
IIITCA00 275gr/m?

(5) MIIII 1SA-1 n $16 \times 145$

(6) IIII III 4 ม $8 \times 100$

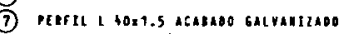

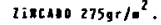

(5) Porexpan 4ta-20kg//3

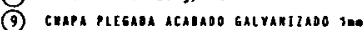

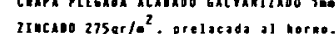

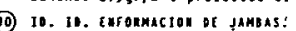

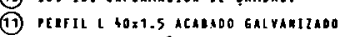

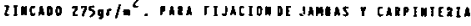

intretaio de suetost

(12) carpintels gxisteats.

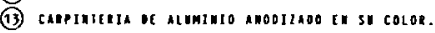

ESQUNA FACHADA VOLADIZO
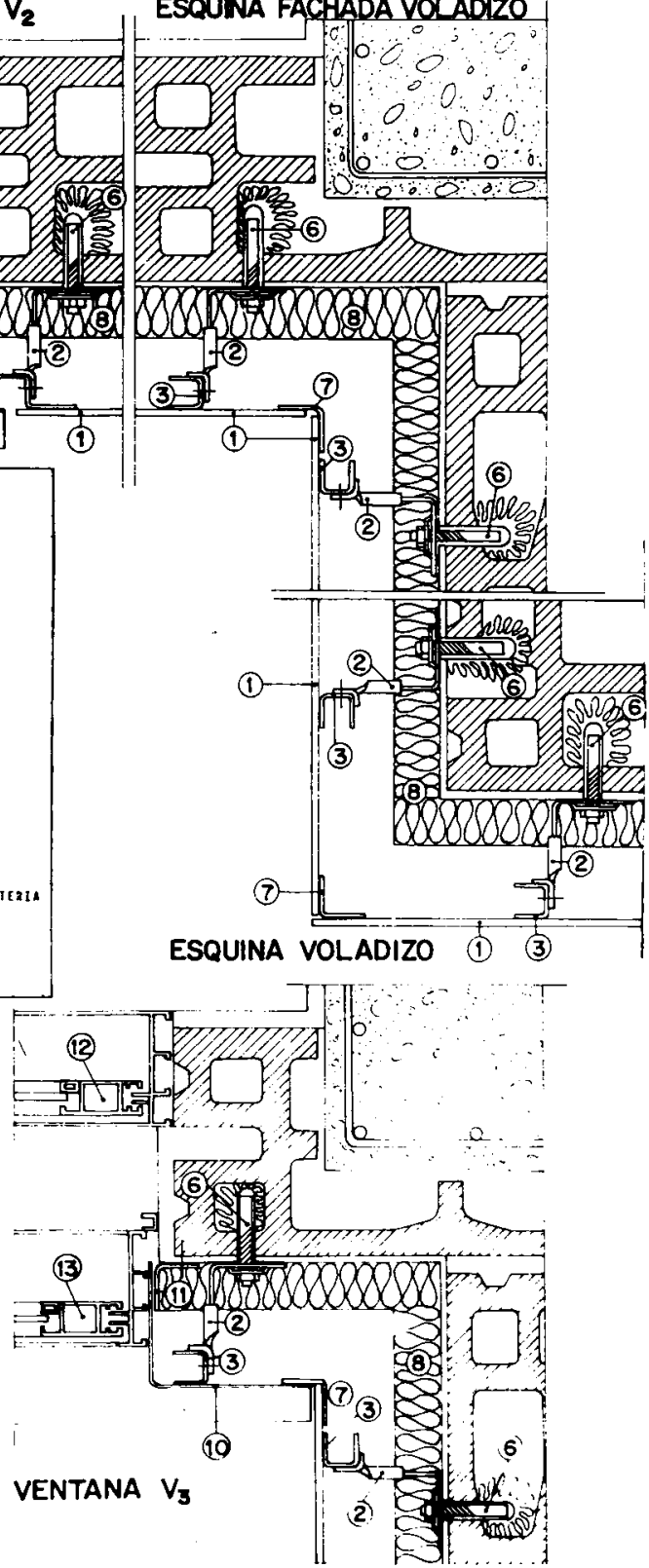
Pese a la posibilidad teórica de intercambiar este material por otro, manteniendo las características fundamentales de este tipo de sistemas, se puede indicar que en la actualidad tal hecho no resulta fácil dentro de un margen de costo competitivo. Ello es debido a que nuestra industria no oferta una gama amplia de materiales con las características de durabilidad, resistencia, estabilidad y ligereza necesarias al efecto.

La existencia de una estructura auxiliar y sus correspondientes elementos secundarios de anclaje y separación del soporte resulta inexcusable en este tipo de sistemas ligeros no autoportantes. En el caso que nos ocupa la estructura se forma a base de montantes verticales formados a base de perfilería de acero galvanizado de $1,5 \mathrm{~mm}$ de espesor. Existen dos tipos de montantes: Los de tipo "OMEGA", que sirven además como elementos de obturación de las juntas verticales entre placas y, por tanto, se sitúan a distancias máximas a ejes de $123 \mathrm{~cm}$; y los de tipo "Un", que se colocan en situación intermedia, quedando finalmente ocultos tras las placas. Ello da lugar a unas distancias horizontales entre apoyos de placas próximas a $10560 \mathrm{~cm}$, que es la luz libre transversal en la que éstas son autoportantes.

Toda la perfilería, tanto en España como en Bélgica, se fabrica por plegado de chapa pregalvanizada en caliente por el sistema Sendzimir, lo que da lugar a la incompleta protección de los cantos de aquélla, obtenida por corte de la bobina original. Tal problema es de relativa magnitud, dado que, al situarse la estructura en un ambiente ventilado y poco agresivo como es la cámara, el avance de la corrosión queda muy dificultado. Sin embargo, su resolución no es fácil de conseguir debido a que no es posible galvanizar a posteriori chapas de menos de $3 \mathrm{~mm}$ de espesor sin que se produzcan alabeos en los perfiles por enfriamiento diferencial. Tal grosor implicaria un cambio sustancial del esquema resistente de la estructura, pues habría que considerar una perfilería de mayor dimensión y canto, tratando de fijarla, exclusivamente, en los niveles de forjado existente.

Esta solución no está experimentada, pero es previsible el considerar que se requeriria un gran aumento en la rigidez de los elementos del conjunto para evitar las vibraciones que la acción del viento provocarian al aumentarse las luces entre apoyos a distancias próximas a los $3 \mathrm{~m}$. Otra alternativa sería la utilización de acero CT36 que, a su vez, tropieza con la dificultad real de disponer de inmediato de pedidos importantes en espesores reducidos (el mínimo es $2 \mathrm{~mm}$ ); asi como con la cuidada ejecución y drenaje del sistema necesarios para evitar que el óxido pudiera refluir al exterior, produciendo manchas en el material de acabado.
Los elementos de apoyo y fijación de la estructura auxiliar a la fachada están constituidos por escuadras de acero galvanizado y contraescuadras deslizantes sobre aquéllas. De esta forma, se pueden conseguir separaciones variables respecto al plano exterior del edificio, corrigiendo planos defectuosos sin gran dificultad. El espesor del material es de $3 \mathrm{~mm}$ como mínimo, lo que permite el galvanizado en caliente posterior a la mecanización de estos elementos. Con este espesor, la rigidez de los elementos es suficiente para garantizar su resistencia con separaciones del plano de acabado respecto al de fachada original de hasta $142 \mathrm{~mm}$; que garantizan la absorción de cualquier desplome o irregularidad normales. Si se requieren separaciones superiores ha de recurrirse a soluciones especiales no previstas en el sistema homologado.

Suponiendo, al igual que se hizo en el apartado anterior, un soporte base de un pie de ladrillo perforado, un aislamiento de $4 \mathrm{~cm}$ de poliestireno de $15 \mathrm{~kg} / \mathrm{m}^{3}$ y una cámara de aire de $5 \mathrm{~cm}$ de espesor medio, el muro final resultante posee un coeficiente de conductividad térmica de $0,488 \mathrm{kcal} / \mathrm{hm}^{2}{ }^{\circ} \mathrm{C}$. Ello implica que, sin tomar en consideración los efectos favorables indicados para los muros ventilados, este sistema es del orden del $12 \%$ más eficaz que el sistema PM. Por otra parte, $y$ al igual que en el caso anterior, el correspondiente estudio de condensación revela que, en condiciones normales, ésta no puede producirse en la superficie interior ni en los intersticios del sistema.

Las ventajas de este tipo de sistemas son múltiples $y$ han sido repetidamente manifestadas en apartados anteriores, pudiendo indicarse aqui las posibles desventajas que aconsejen, en un momento dado, el no tomarlos en consideración:

- Requieren una estructura auxiliar y elementos secundarios de fijación y anclaje.

- No constituyen un "sistema integral», dado que deben ser suplementados con materiales adecuados en los puntos conflictivos de diseño, como son jambas, remates, juntas, etc.

- Suponen una mayor complejidad constructiva y requieren mano de obra de mayor especialización, por lo que, en general, son más costosos que los sistemas sin cámara.

- Ocupan mayor espacio en planta que el sistema PM.

- Su acabado es discontinuo, mostrando una trama de juntas lineales, $y$ las placas ofrecen un aspecto satinado, lo que requiere un cuidado especial a la hora de su integración en el entorno urbano. 
- La oferta de materiales adecuados de acabado es muy limitada y, generalmente, se circunscribe a productos de importación.

- Al igual que los sistemas sin cámara ofrecen una mala respuesta ante los problemas que se plantean en las plantas bajas, si bien, no tienen costos importantes de conservación en general, y se comportan mejor ante el fuego.

Se ofrece documentación gráfica de la única experiencia en curso de este sistema, relativa a la operación de Rehabilitación del Barrio de Santa Ana de Madrid, realizada por los autores del presente artículo.

\section{SISTEMAS PESADOS CON CAMARA EXTERIOR. EL SISTEMA DE MURO DOBLE (MD)}

El sistema consta esquemáticamente de un material aislante, adherido a la fachada base existente, y de un muro exterior de medio pie de ladrillo, de nueva ejecución, convenientemente apeado y anclado al soporte.

En todo lo relativo al material aislante, poco cabe añadir a lo expuesto en anteriores apartados, dado que el problema es idéntico desde este punto de vista. Unicamente, indicar aquí que la mejor protección ante el fuego y la humedad exterior proporcionada por el muro de medio pie, así como su superior resistencia térmica, permiten, de una parte, considerar seriamente la alternativa del empleo del PU proyectado, y de otra, reducir sensiblemente los espesores de aislamiento.

En cuanto al acabado de fábrica caben mencionar varias características importantes:

- Su gran versatilidad, dado que puede ejecutarse a cara vista o para recubrir, lo que le hace capaz de lograr su integración arquitectónica en cualquier medio urbano de la geografía española.

- Su calidad de acabado y sus posibilidades de diseño. Existen abundantísimos ejemplos, tanto en Madrid como en el resto de España de fábricas, que, cuidadosamente ejecutadas, confieren una gran nobleza al edificio en que se asientan.

- La importante tradición con que la albañilería cuenta en nuestro pais. Esta permite un mejor entendimiento entre proyectista y operario, así como la incorporación de la experiencia de este último a la hora de estudiar las soluciones necesarias a los problemas que se pudieran plantear.

- Su gran durabilidad y la ausencia total de costos de mantenimiento, particularmente en la ejecución de la fábrica a cara vista con ladrillo de calidad suficiente.
- El consumir material de fabricación española y un importante porcentaje de mano de obra. Ello reduce la dependencia del sistema a tecnologías exteriores, y sus ligeros sobrecostos repercuten en la ocupación de la población, en lugar de trasferirse a empresas que nos son ajenas.

- Su elevada resistencia, tanto mecánica, como al impacto y a las agresiones climáticas, por lo que resuelven todos los problemas que se plantean a la hora de rehabilitar una fachada.

En resumen, el acabado con fábrica de ladrillo reúne todas las ventajas de los sistemas ligeros con cámara exterior y aporta soluciones de todo tipo a los problemas inherentes a la propia ligereza de aquéllos.

Sin embargo, su planteamiento desde el proyecto requiere un concienzudo estudio previo, dado que la fá. brica posee dos características que así lo aconsejan. Estas son: su elevado peso propio (aproximadamente $200 \mathrm{~kg} / \mathrm{m}^{2}$ ) y su fragilidad; y obligan necesariamente a resolver adecuadamente, tanto el apoyo de ésta, en condiciones de indeformabilidad del mismo, como su libertad de movimiento diferencial respecto al soporte.

En cuanto a la característica del peso de la fábrica, conviene recomendar que, en tanto no exista una experiencia suficiente de este sistema, y, en cualquier caso, siempre que no sea posible una peritación segura de la estructura original, no se utilice este sistema para edificios de más de cuatro plantas y se sustente el nuevo muro en una cimentación propia capaz de resistir la totalidad de la carga. Todo ello, sin olvidar la necesidad del anclaje, con cierta intensidad, a la fábrica existente.

Como ya se vio en el apartado relativo a la Magnitud del Problema, la limitación temporal en el número de alturas supone que, a pesar de todo, se cubre un amplísimo margen de la demanda. En cualquier caso $y$, hoy por hoy, éste es el único sistema que resuelve a satisfacción la vulnerabilidad del resto de los sistemas en plantas bajas.

La fragilidad de la fábrica impone una serie de condicionantes en su diseño, de forma que se consiga, simultáneamente, un anclaje suficientemente solidario con el soporte, y se conserven las posibilidades de deformabilidad propias. Asi, la nueva fábrica deberá pre. sentar juntas de retracción y dilatación a no más de $12 \mathrm{~m}$ medidos en horizontal; deberá quedar indepen. dizada de la cumbrera del edificio en su remate superior y deberá anclarse convenientemente en torno a los huecos y en las esquinas de jambas y dinteles de los mismos. 
A los efectos del diseño constructivo de la fábrica conviene recordar que en países como Francia, Bélgica, Holanda, Alemania y Estados Unidos, los muros de doble hoja se han venido construyendo intensamente en obras de nueva planta y se dispone de normativa especifica relativa a sus espesores, métodos de cálculo, forma y disposición de los anclajes, etc. Si bien toda la información allí contenida no es directamente aplicable al caso de la rehabilitación, si supone un punto de partida en el que muchos problemas quedan resueltos.

En este caso resulta inexcusable la recuperación de la técnica de puesta en obra del ladrillo previamente humectado. Como es sabido, la impermeabilidad y las características resistentes de la fábrica dependen directamente de la inexistencia de fisuras por retracción en las llagas. Ello se consigue dotando a las piezas cerámicas del contenido de agua suficiente para que no desequen aceleradamente el mortero que las rodea.
Uno de los elementos más importantes de este sistema lo constituyen los anclajes entre ambas fábricas. En general, su densidad de instalación es superior a la necesaria en los sistemas ligeros (de 2 a $2,5 \mathrm{ud} / \mathrm{m}^{2}$ frente a $1,2 \mathrm{ud} / \mathrm{m}^{2}$ ), pero no necesitan de la estructura suplementaria de éstos. La nueva fábrica deberá anclarse necesariamente en los niveles de forjado y en torno a los huecos existentes, disponiéndose además anclajes en hileras al tresbolillo en paños intermedios.

El hecho común de que la fábrica primitiva esté deteriorada fuertemente, o bien presente materiales huecos, redunda en un incremento de costo de los anclajes, siendo a menudo preciso recurrir a fijaciones capaces de macizar el material base por medio de la inyección de resinas de dos componentes. Suele ser interesante el considerar la inserción de refuerzos en la fábrica, colocando cada cierto número de hiladas, en la llaga correspondiente, una celosia ligera de acero galvanizado en conexión con los anclajes previstos.

\section{SISTEMA MD. PLANTA. ALZADOS. ANCLAJES. REHABILITACION «GRUPO LOS CASTILLOS. SAN BLAS》.}

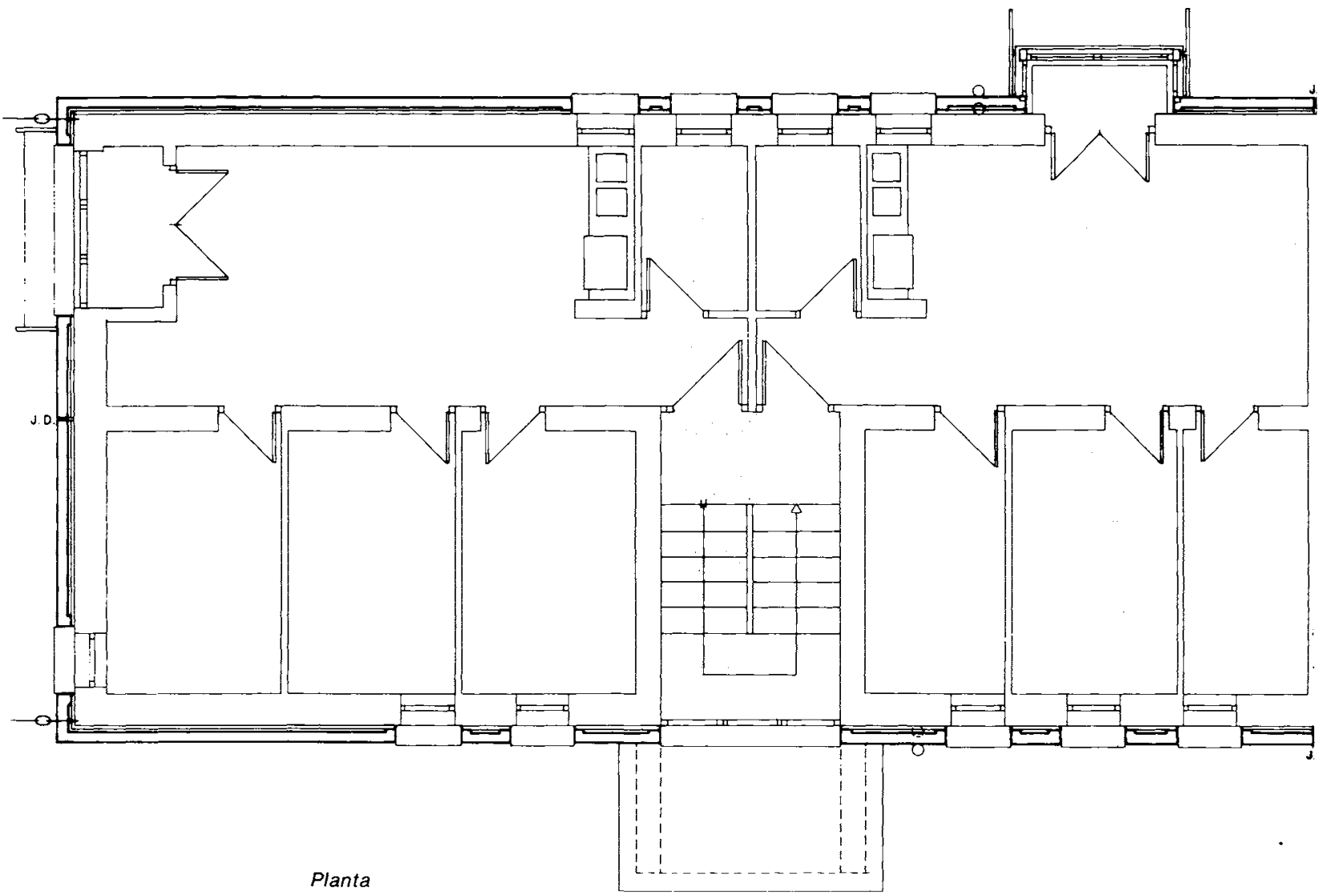




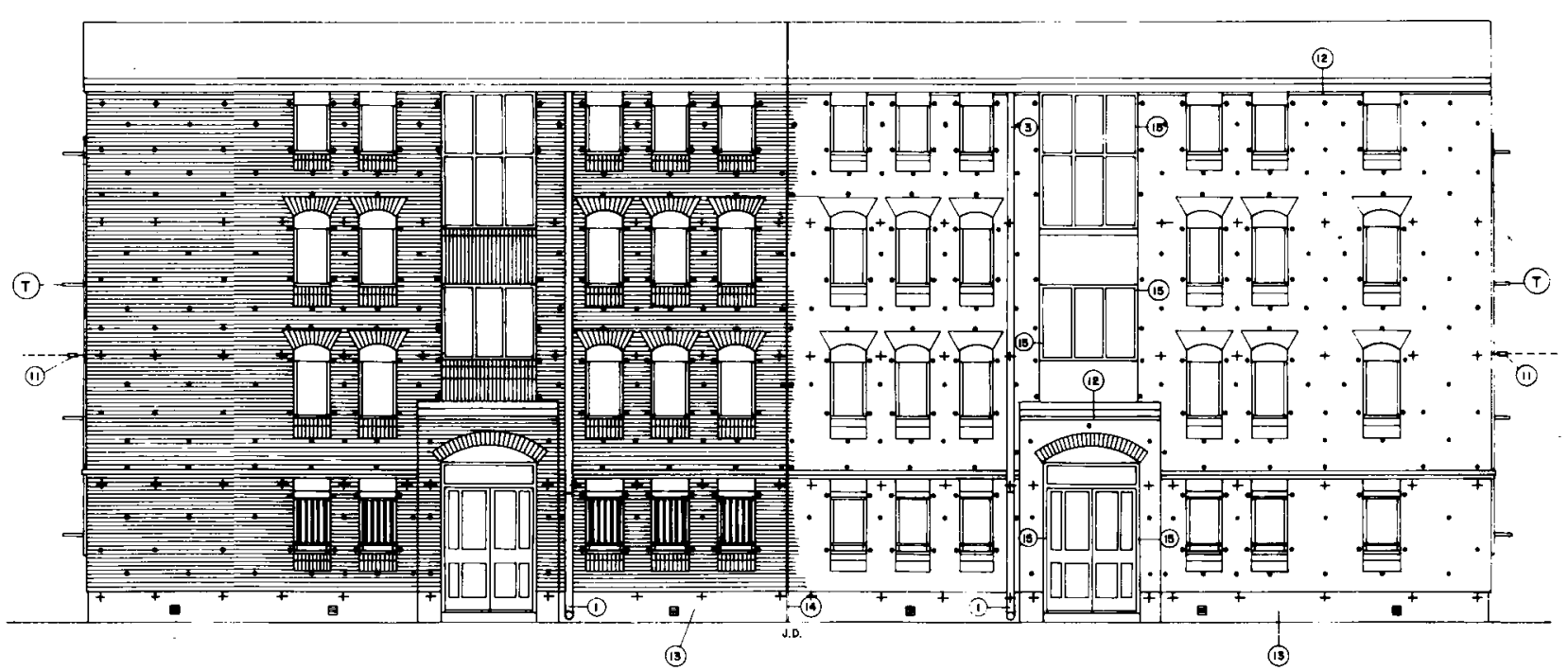

Alzado principal

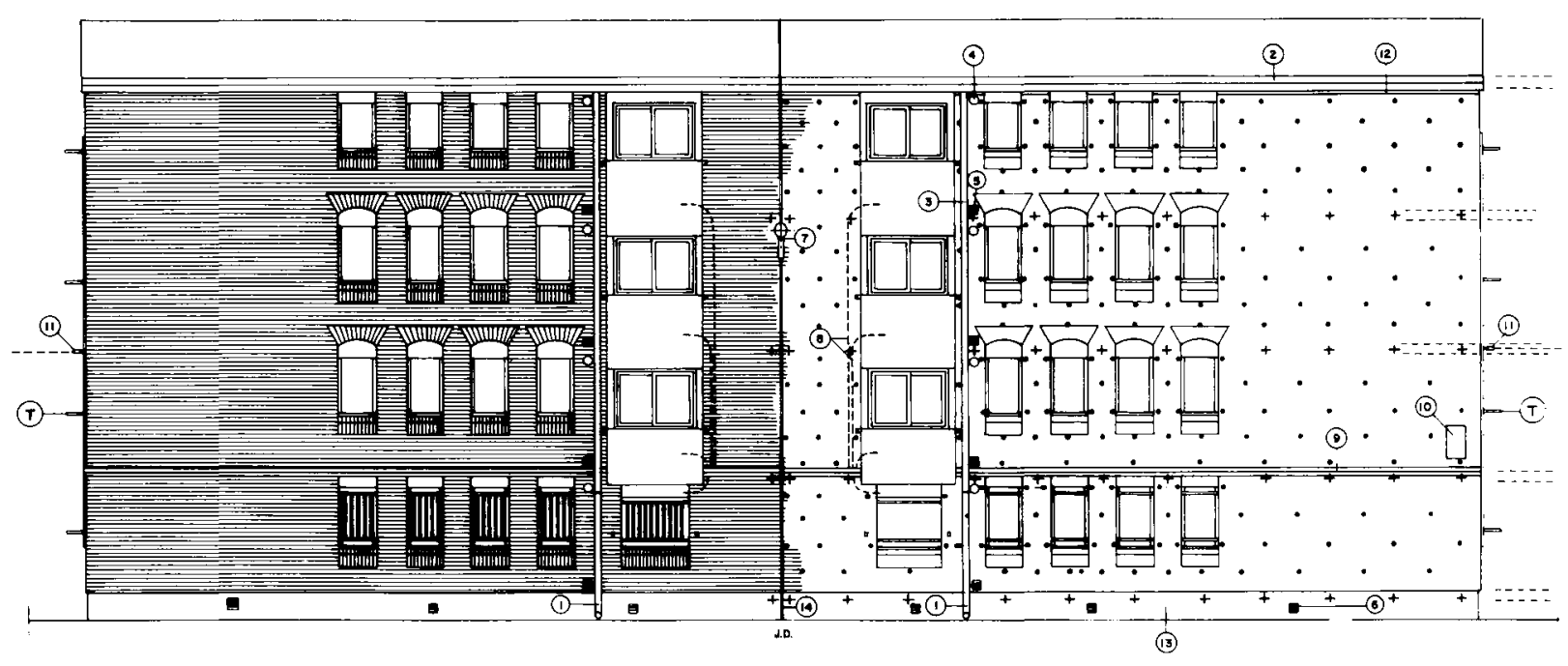

Alzado posterior

En general, para realizar el adecuado estudio de los problemas constructivos relativos a este tipo de sistemas, se recomienda la previa consulta de bibliografía especializada (ver ref. 19), así como el asesoramiento de personal experimentado.

Suponiendo, en idénticas condiciones que en los casos anteriores, un soporte base de 1 pie de ladrillo perforado, y unas condiciones de aislamiento y cámara de aire equivalentes, el coeficiente de conductividad térmica del sistema es de $0,449 \mathrm{kcal} / \mathrm{hm}^{2}{ }^{\circ} \mathrm{C}$, es decir, resulta ser un $21 \%$ más eficaz que los sistemas no ventilados y un $9 \%$ más eficaz que los sistemas ligeros.

Al igual que en los casos anteriores no se detecta la posibilidad de aparición de condensaciones, tanto superficiales como intersticiales.

Las ventajas de este sistema con respecto a los anteriormente expuestos son manifiestas y han quedado suficientemente expresadas. En su detrimento cabria sólo indicar que consume mayor cantidad de espacio exterior $(20 \mathrm{~cm})$ y que, hoy por hoy, tiene su empleo limitado a edificios de no más de cuatro plantas.

La experimentación concreta de este tipo de sistemas se ciñe, exclusivamente, a la rehabilitación de las viviendas de planta baja en el ya citado Barrio de Santa Ana, en Madrid, cuya obra ha sido iniciada recientemente bajo proyecto y dirección de los autores de es. te artículo. 
乡

อั

Oุ

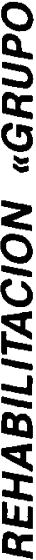

㟧

$\frac{5}{5}$

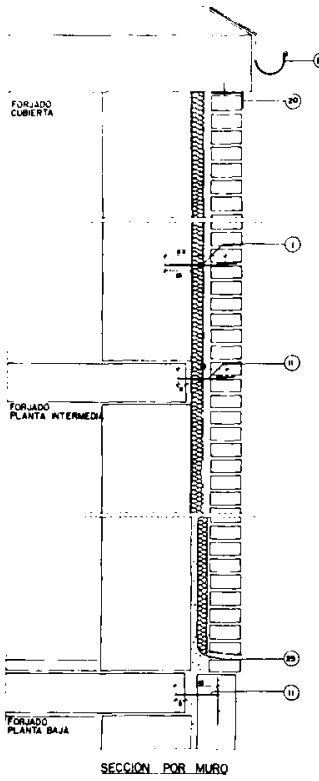

0

(3)

Bi

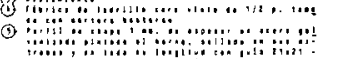

(1)

3.1.

a.

(4.).

(a.)

:

(2)

政

(3)

Q⿻)

(2.

and

(1)
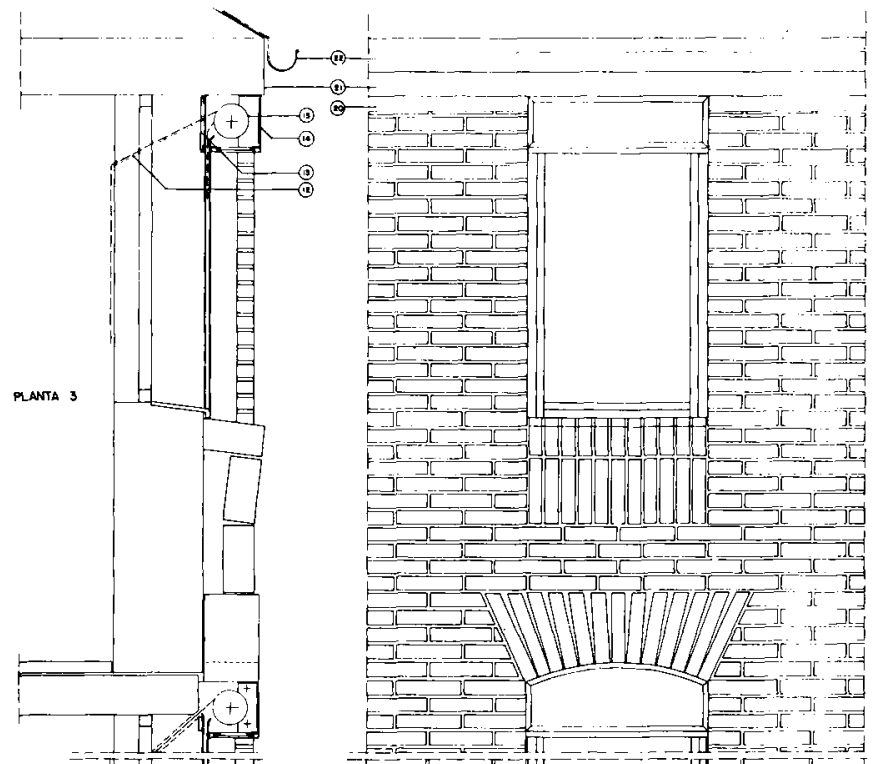

$==-2=-21$
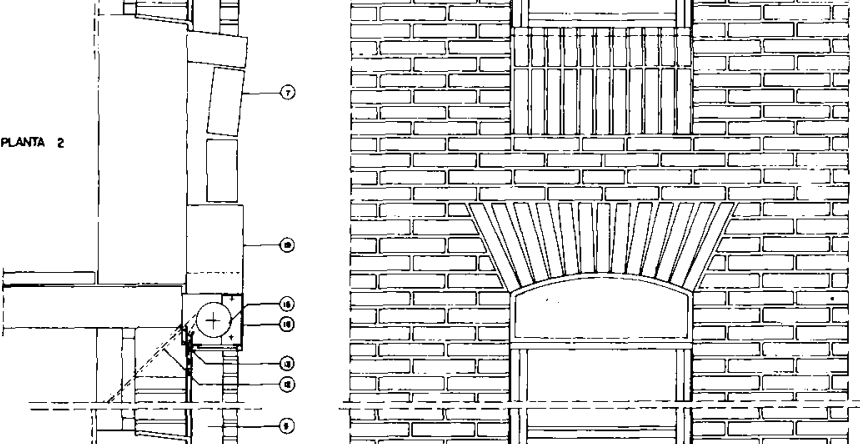

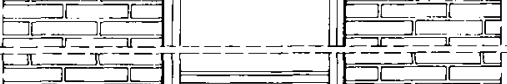
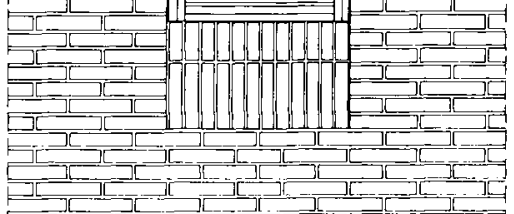

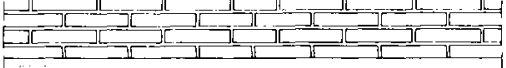

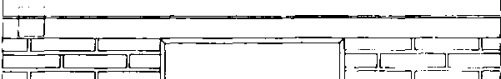

ard
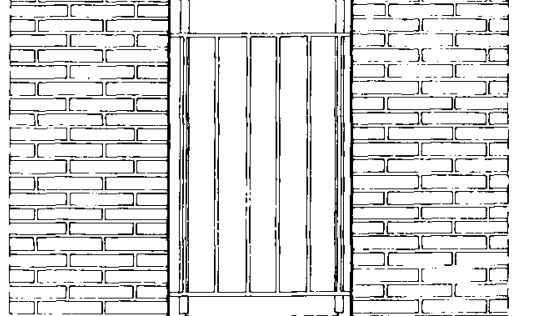

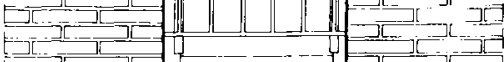

a

य

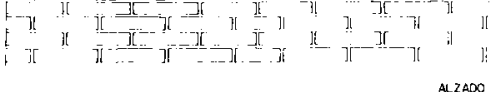

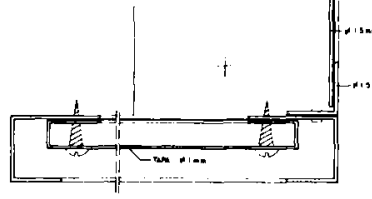

DETALLE DE CAPALZZADO
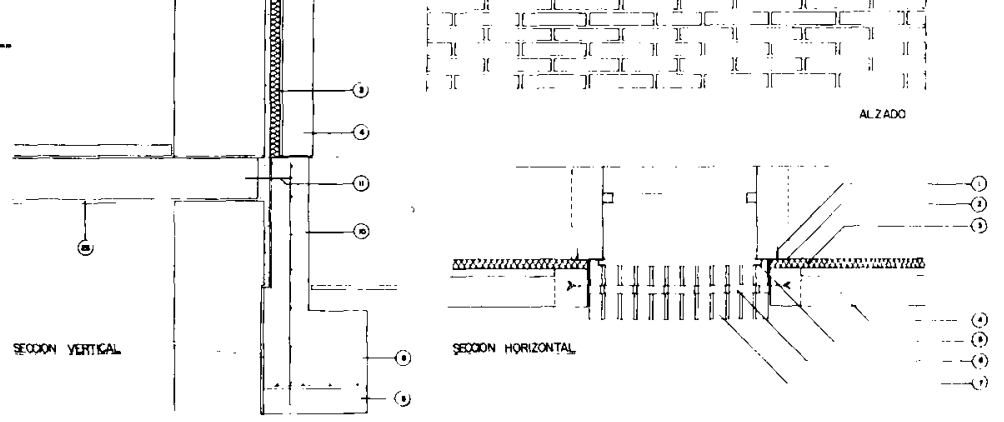
Con anterioridad, los mismos arquitectos y otros realizaron, en 1985, un proyecto de rehabilitación con este sistema en el conjunto "Los Castillos del Barrio de San Blas, en Madrid". Tras un largo debate, fue finalmente sustituido por decisión de la Administración autonómica por el PM, en base a que un minucioso estudio comparativo de los costos de ejecución de ambos sistemas favorecía al último en un $2,5 \%$ del presupuesto total, olvidándose, tanto los costos indirectos de mantenimiento, como del resto de ventajas aquí enunciadas. Se ofrece documentación gráfica de este proyecto.

\section{SISTEMAS LIGEROS CON CAMARA INTERIOR. EL SISTEMA GRC}

El sistema consiste esquemáticamente en la total prefabricación en taller de paneles de doble cáscara con aislamiento intermedio y, en su caso, carpintería incorporada para su directa instalación en obra.

La única experiencia real desarrollada en el caso de la rehabilitación es la ejecución de un bloque piloto, en el Barrio de Santa Ana, de Madrid, por el arquitecto Gerardo Pérez Calleja y otros.

No entraremos aquí en la problemática que encierra en sí mismo el material GRC, puesto que su estudio es suficientemente complejo como para ocupar, por si sólo, textos mucho más amplios que el que nos ocupa. Su fabricación en taller especializado hace que sean muy pocas las empresas que, hoy en dia, pueden ofertarlo en España en condiciones suficientes de garantía y calidad. Desde el punto de vista del proyectista y del director de la obra, cabe indicar, tan sólo, y de un lado, que el diseño de los paneles debe realizarse en total coordinación con el fabricante, y de otro, que la ejecución prefabricada dificulta el control de la misma, cuyos ritmos, tiempos de curado, etc. no pueden ser vigilados de forma estricta y dependen del interés y profesionalidad del fabricante. Por ello habrán de in- tensificarse, en estos casos, las campañas de control por laboratorio del producto acabado.

El empleo de sistemas como el que aqui se estudia surge del intento de paliar el inconveniente de costo en tiempo y mano de obra que supone la ejecución in situ. Es por ello que el sistema se prefabrica íntegramente con inclusión del aislamiento. Ello da lugar a los problemas funcionales ya enunciados, puesto que se dispone la cámara en una posición inadecuada.

Por otra parte, las supuestas ventajas de la prefabricación no repercuten en una reducción de los precios, sino que, por el contrario, este sistema es el menos económico de todos los estudiados. Esto se debe, por un lado, a que la situación del mercado es casi monopolista, y por otro, a que la solución es en sí misma costosa.

A su vez, la inserción de un sistema constructivo de gran rigidez de diseño sobre fachadas de ejecución de. fectuosa da lugar a un problema complejo de estudio y control de las tolerancias. En cualquier caso, el sistema requiere de unas posibilidades amplias de repetición de los tipos de paneles, con el fin de poder amor. tizar los moldes. Por tanto, no es extrapolable al caso de edificios singulares entre medianerías, insertos en un casco urbano, con el que, además, pueden presentarse problemas de adaptación formal.

Dado que, como ya se ha dicho, el sistema cuenta con una experimentación real suficientemente válida, ha de ser tomado en consideración $y$, a continuación, se acompaña documentación gráfica relativa al proyecto anteriormente citado en el Barrio de Santa Ana, remitiéndose a todos cuantos deseen una mayor información al respecto, tanto a las referencias citadas en la Bibliografía, como al "Informe técnico sobre la idoneidad teórica de dos soluciones diferentes para tratamiento de fachadas en bloques de la Promoción Santa Ana-Fuencarral" emitido por el Instituto Torroja, en enero de 1986. 
SISTEMA GRC. DESPIECE DE FACHADA. PROYECTO DE BLOQUE PILOTO. SANTA ANA. MADRID.

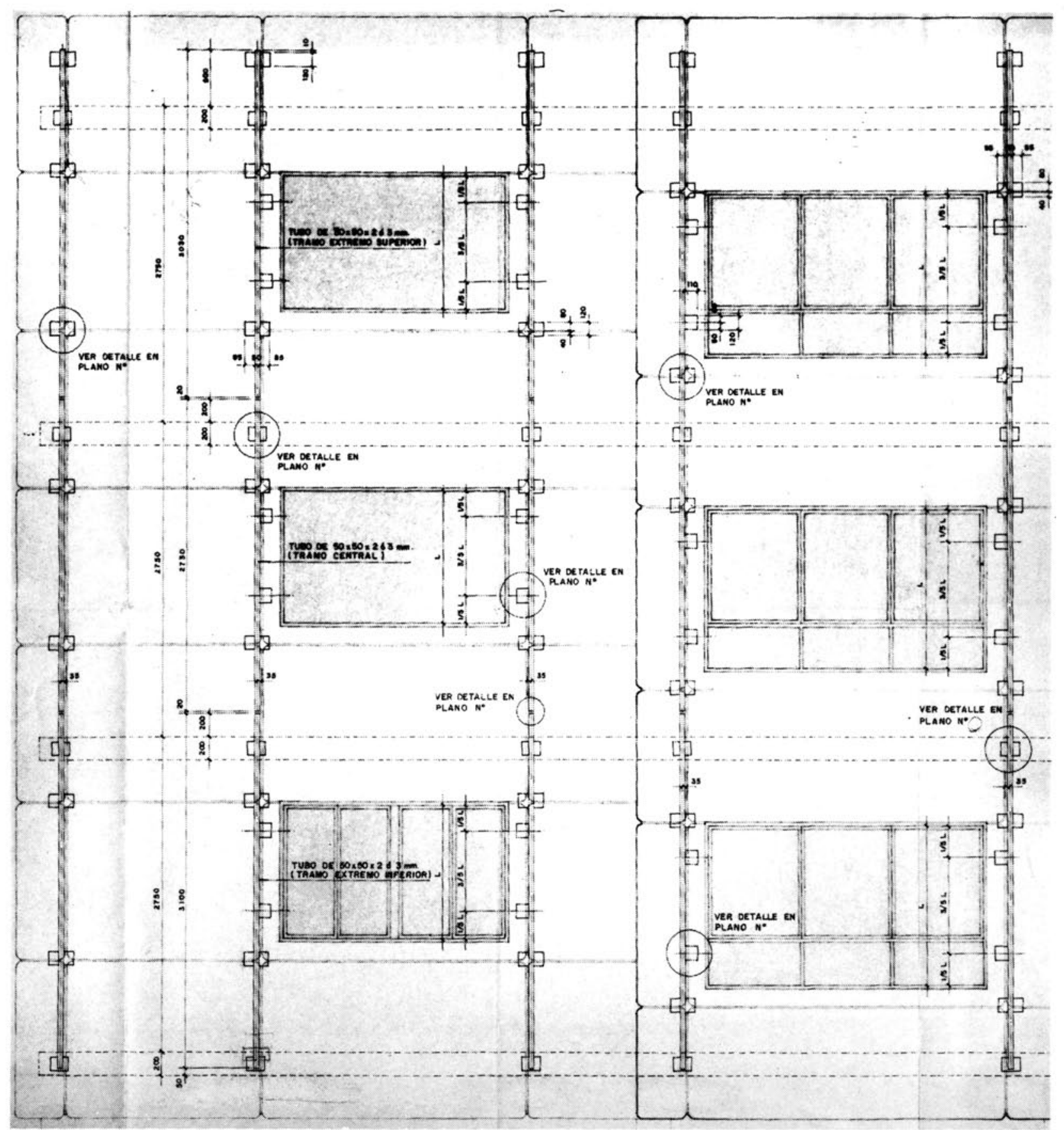


SISTEMA GRC. SECCION POR DINTEL. PROYECTO DE BLOQUE PILOTO.

SANTA ANA. MADRID.

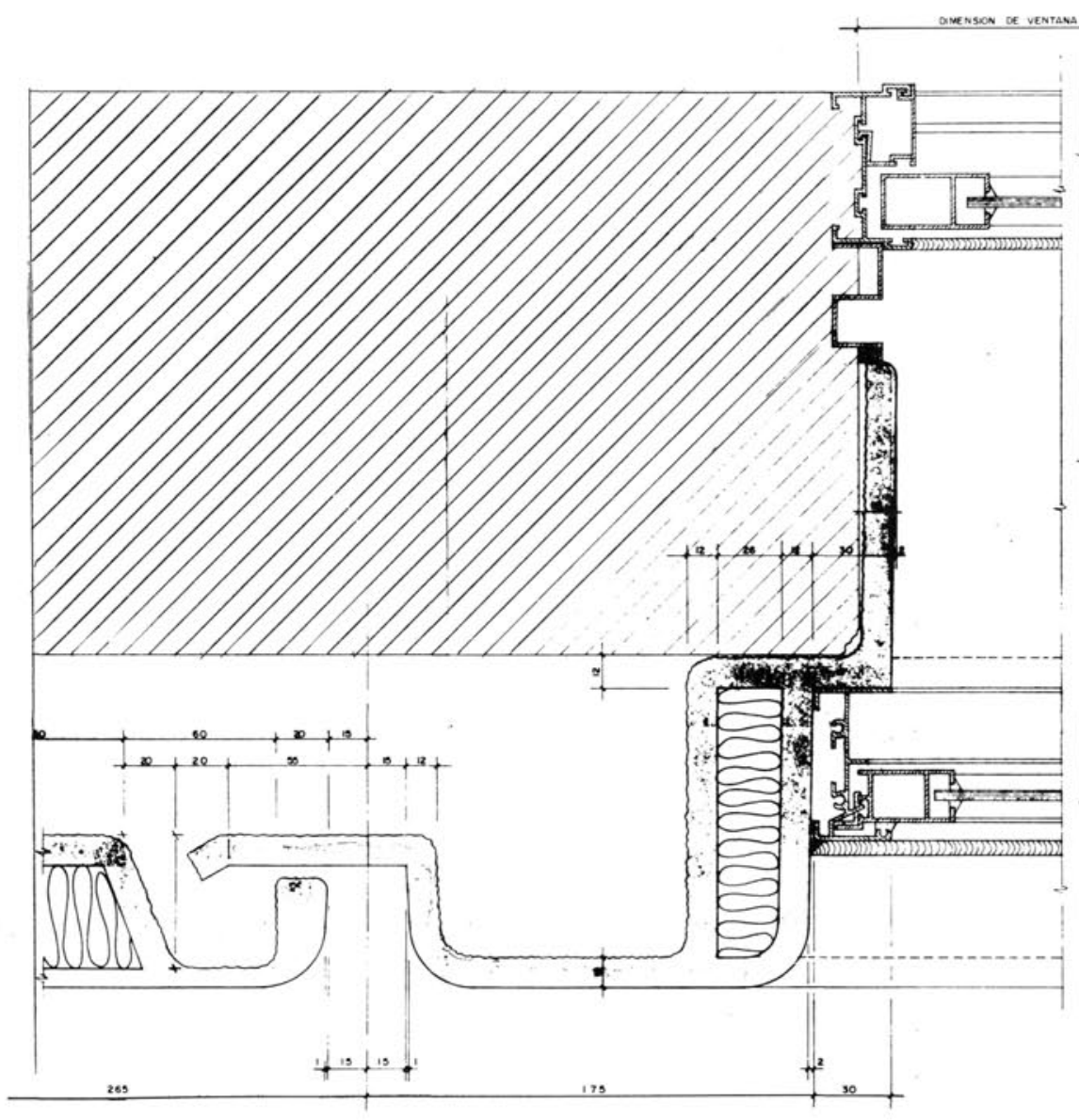

(C) Consejo Superior de Investigaciones Científicas (c) Consejo Superior de Investigaciones Cientificas
Licencia Creative Commons 3.0 España (by-nc)

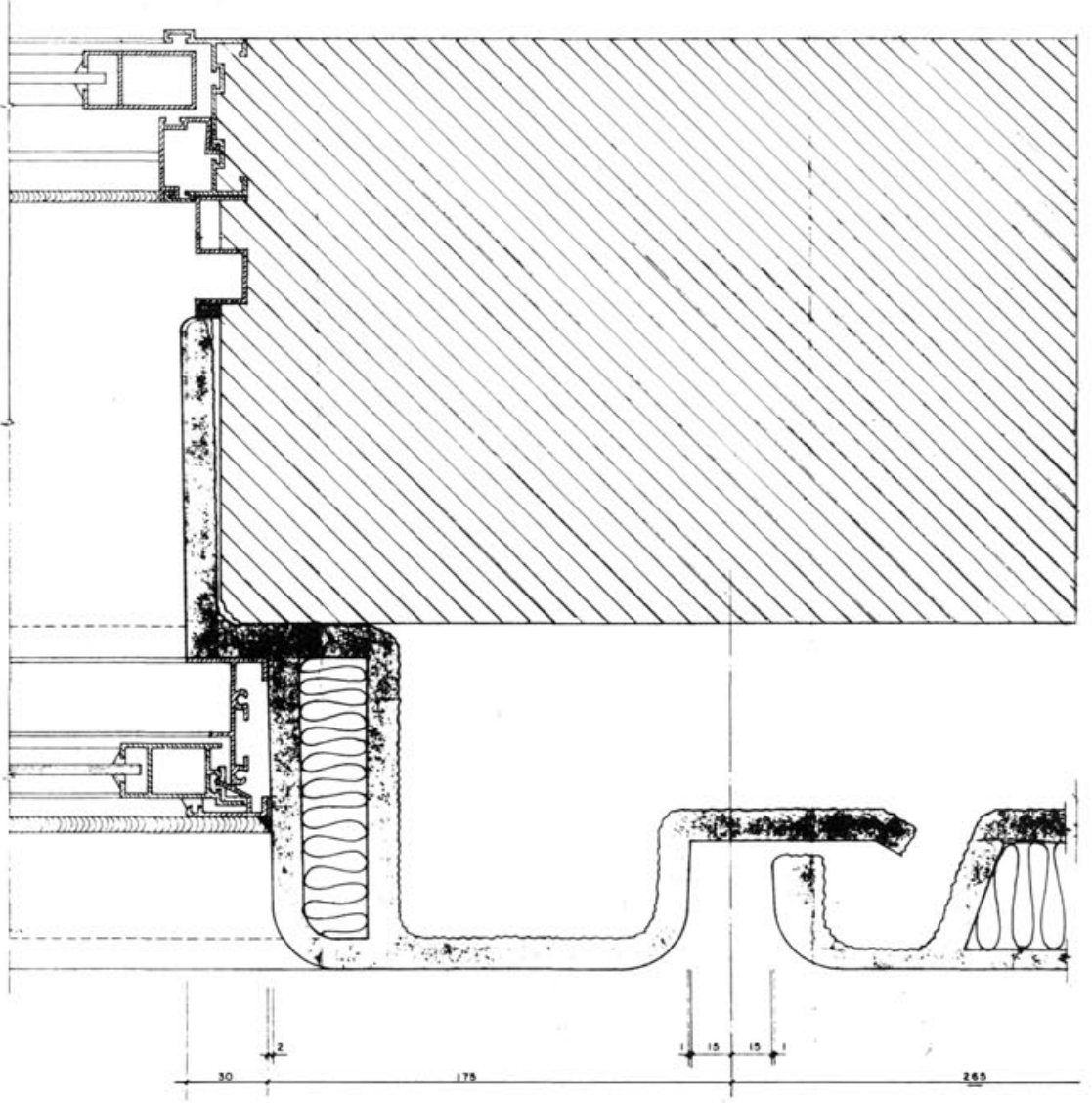

http://informesdelaconstruccion.revistas.csic.es 
SISTEMA GRC. SECCION HORIZONTAL. PROYECTO BLOQUE PILOTO. SANTA ANA. MADRID.

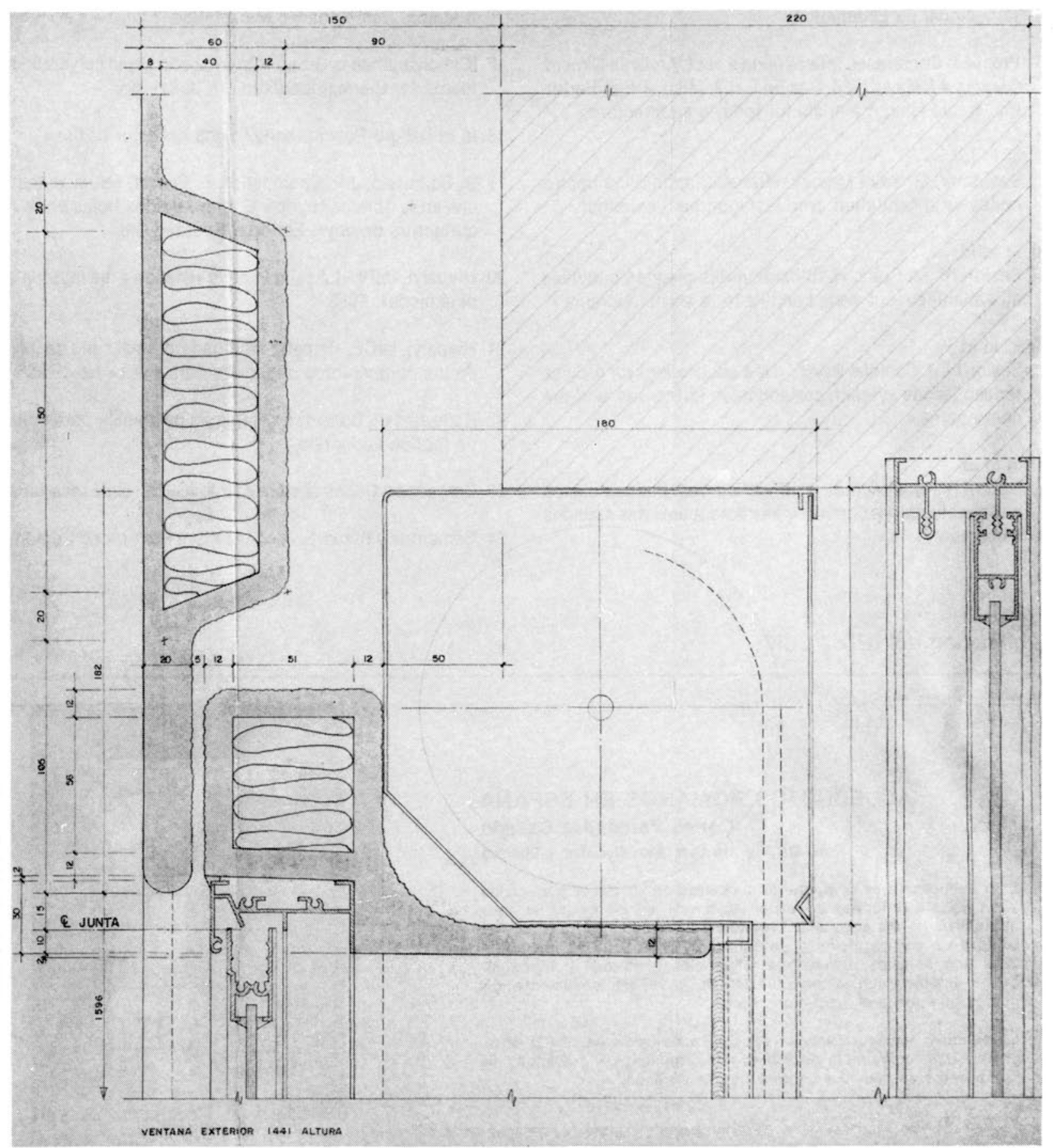




\section{BIBLIOGRAFIA Y FUENTES}

1 Norma básica NBE-CT79, sobre Condiciones Térmicas en los Edificios (R.D. 2429/79).

2 Norma Básica NBE-CPI81, sobre Condiciones de Protección Contra Incendios en los Edificios (R.D. 2059/81).

3 Protección a la Rehabilitación del Patrimonio Residencial y Urbano (R.D. 2329/83).

4 Instituto de la Vivienda de Madrid. Consejeria de Política Territorial de la Comunidad de Madrid. Datos estadísticos sobre el parque de vivienda de promoción pública.

5 Censo 1980 del Estado de la Edificación. Madrid. Instituto nacional de Estadística.

6 Premiére Conférence Internationale sur L'Amiante-Ciment. Cannes 4-7 Mayo 1986. Sesión I. H.J. Miko. «High Performance cladding materials for today's architecture.”

7 Id id id

Sesión IV. G. Saint-Macary. "Rehabilitation d'inmuebles collectifs d'habitation avec isolation par l'exterieur."

8 Id id id

Sesion IV. M. Spitz. "L'utilisation des plaques ondulees en amianteciment dans l'architecture contemporaine."

9 Id id id

Sesion IV. J. Coombs-Payac. "New applications for A/C materials: facade system, prefabricated structures, and fire doors cores.n

10 Id id id

Sesion IV. M. Millereux. "Utilisation des plaques planes en amianteciment comme "peau estérieure" des maisons à ossature bois.n
11 P. Baronnie. (Ingeniero CSTB). "Manual para la puesta en obra de revestimientos delgados sobre Aislamiento. El buen ejemplo del aplicador K'APLIC." Traducción: A. Ruiz Duerto. I.E.T.cc. Madrid.

12 P. Baronnie. "Enduit Minces sur Isolants: les desordres, et comment les éviter."

13 Documentos de Idoneidad Técnica para Sistemas de Ais. lamiento térmico exterior. I.E.T.cc.

14 Eternit. Dossier 5. Sistema Ventisol-Galva.

15 Eternit. Dossier Materiales Eternit planos. Glasal.

16 Segundas Jornadas de Plásticos Espumados en la Construcción. Barcelona 5-6 Marzo 1986.

$17 \mathrm{ICl}$ Polyurethanes Group. «Spray-applied rigid polyurethane foams for thermal insulation in building."

18 Id id. "Rigid Polyurethane foams behavior to fire."

19 D. Bernstein, J.P. Champetier, F. Peiffer. "Nuevas técnicas en la obra de fábrica. El muro de dos hojas en la Arquitectura de hoy". Editorial Gustavo Gili.

20 Hispalyt, IMPI. «La calidad de la vivienda y los materiales cerámicos", 1985.

21 Hispalyt, INCE. "Impermeabilidad frente al agua de lluvia de los cerramientos de ladrillo cara vista." Nov. 1985.

22 Halfeneisen. Dossier de sistemas de anclaje para muros de fábrica de ladrillo.

23 Dragados y Construcciones S. A. "G.R.C. Guia resumida."

24 Cementos y fibras, S. A. "Glassfibre Reinforced Cement.»

\section{Publicación del IETcc/CSIC}

\section{ACUEDUCTOS ROMANOS EN ESPAÑA Carlos Fernández Casado \\ Prof. Dr. Ing. de Caminos, Canales y Puertos}

Esta publicación se compone de una serie de articulos, publicados en la Revista "Informes de la Construcción", en los cuales se hace un análisis de los acueductos romanos que existen en España y el balance de las condiciones de conservación en que se encuentra cada uno de ellos, incluyendo referencias históricas y literarias. Se ha ilustrado con la reproducción de la valiosa documentación gráfica que posee el prestigioso autor.

Un volumen encuadernado en couché, a dos colores, de $21 \times 27$ centimetros, compuesto de 238 páginas, numerosos grabados, dibujos, fotos en blanco y negro y figuras de linea.

Precio: España, 1.500 ptas., 21 \$ USA.

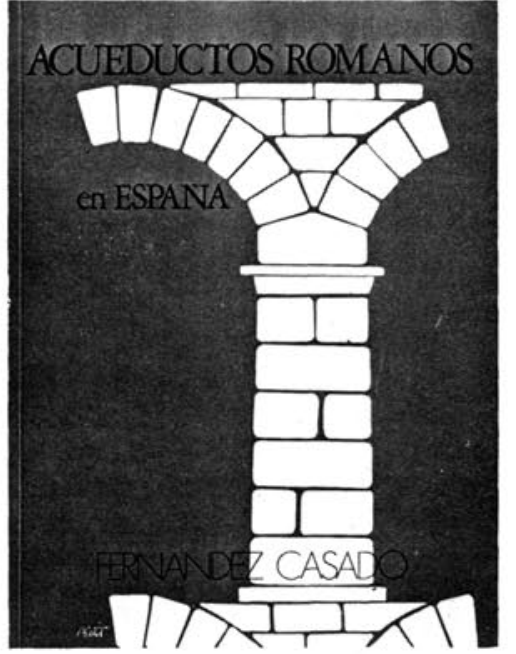

